\title{
Projected changes of snow conditions and avalanche activity in a warming climate: the French Alps over the 2020-2050 and 2070-2100 periods
}

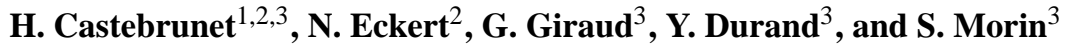 \\ ${ }^{1}$ INSA de Lyon, Laboratoire LGCIE, 20 Avenue des Arts, Bât. J.C.A. Coulomb, 69621 Villeurbanne, France \\ ${ }^{2}$ UR ETGR, IRSTEA/Université de Grenoble Alpes, BP 76, 38402 Saint Martin d'Hères, France \\ ${ }^{3}$ Météo-France - CNRS, CNRM-GAME UMR 3589, Centre d'Etudes de la Neige, 1441 rue de la Piscine, \\ 38400 Saint Martin d'Hères, France
}

Correspondence to: H. Castebrunet (helene.castebrunet@insa-lyon.fr)

Received: 25 November 2013 - Published in The Cryosphere Discuss.: 23 January 2014

Revised: 11 July 2014 - Accepted: 17 July 2014 - Published: 15 September 2014

\begin{abstract}
Projecting changes in snow cover due to climate warming is important for many societal issues, including the adaptation of avalanche risk mitigation strategies. Efficient modelling of future snow cover requires high resolution to properly resolve the topography. Here, we introduce results obtained through statistical downscaling techniques allowing simulations of future snowpack conditions including mechanical stability estimates for the mid and late 21st century in the French Alps under three climate change scenarios. Refined statistical descriptions of snowpack characteristics are provided in comparison to a 1960-1990 reference period, including latitudinal, altitudinal and seasonal gradients. These results are then used to feed a statistical model relating avalanche activity to snow and meteorological conditions, so as to produce the first projection on annual/seasonal timescales of future natural avalanche activity based on past observations. The resulting statistical indicators are fundamental for the mountain economy in terms of anticipation of changes.

Whereas precipitation is expected to remain quite stationary, temperature increase interacting with topography will constrain the evolution of snow-related variables on all considered spatio-temporal scales and will, in particular, lead to a reduction of the dry snowpack and an increase of the wet snowpack. Overall, compared to the reference period, changes are strong for the end of the 21st century, but already significant for the mid century. Changes in winter are less important than in spring, but wet-snow conditions are
\end{abstract}

projected to appear at high elevations earlier in the season. At the same altitude, the southern French Alps will not be significantly more affected than the northern French Alps, which means that the snowpack will be preserved for longer in the southern massifs which are higher on average.

Regarding avalanche activity, a general decrease in mean $(20-30 \%)$ and interannual variability is projected. These changes are relatively strong compared to changes in snow and meteorological variables. The decrease is amplified in spring and at low altitude. In contrast, an increase in avalanche activity is expected in winter at high altitude because of conditions favourable to wet-snow avalanches earlier in the season. Comparison with the outputs of the deterministic avalanche hazard model MEPRA (Modèle Expert d'aide à la Prévision du Risque d'Avalanche) shows generally consistent results but suggests that, even if the frequency of winters with high avalanche activity is clearly projected to decrease, the decreasing trend may be less strong and smooth than suggested by the statistical analysis based on changes in snowpack characteristics and their links to avalanches observations in the past. This important point for risk assessment pleads for further work focusing on shorter timescales. Finally, the small differences between different climate change scenarios show the robustness of the predicted avalanche activity changes. 


\section{Introduction}

In temperate mountainous areas, snow is a major component of the water cycle. As an important element of the critical zone at the interface between atmosphere, geosphere, ecosystems and human societies, it has key impacts on geomorphological processes, biodiversity and the tourism industry. As a consequence, since high-altitude ( $3000 \mathrm{~m}$ and more) areas have been shown to be highly sensitive to climate change (Beniston, 2003), understanding the responses of the snowpack to the ongoing warming, related impacts and potential feedbacks (e.g. albedo change) is of major environmental (e.g. Keller et al., 2005) and economic (e.g. Elsasser and Buerki, 2002; Gonseth, 2013) interest. This can be achieved by studying links between climate and snow cover for present conditions, which includes an assessment of changes already measurable using various observation series, and by quantifying changes to be expected in the future, using snow and regional climate simulations fed by global climate change scenarios.

Recent climate change in mountainous areas is now fairly well documented, for instance in the European Alps (e.g. Beniston et al., 1997). Even if it has not been constant, with periods of slow temperature increase or even cooling, the warming since the end of the Little Ice Age $(\sim 1850)$ has been marked and accelerated over the 1985-2000 period (e.g. Beniston, 2005b). Following studies on larger spatial scales (e.g. Brown, 2000; Mote, 2003; Huntington et al., 2004; McCabe and Wolock, 2010), several studies have documented decreases in snow precipitation, snow depths, snow cover durations or snow water equivalent in many countries of the Alpine region (e.g. Falarz, 2002, 2004; Laternser and Schneebeli, 2003; ONERC, 2008; Valt and Cianfarra, 2010; Serquet et al., 2011; Marty and Meister, 2012). Increased variability has also been observed, especially for winter temperatures, inducing an increasing number of warm winter spells (Beniston, 2005a). Lastly, efforts have been made to quantify elevation-dependent effects on warming (Rangwala and Miller, 2012) and their complex interaction with the freezing level, leading to less marked trends in snowpack depth and duration at high altitude (Moran-Tejeda et al., 2013). For the specific case of the French Alps, a fairly complete picture of recent changes is available, including subregional, altitudinal and seasonal gradients, thanks to systematic point measurement analysis (Dumas, 2012) and snowpack and meteorological reanalyses (Durand et al., 2009a, b).

Concerning future snowpack evolution, first estimations have been obtained through simple extrapolations of current observed trends (e.g. Beniston et al., 2003) or sensitivity studies using snowpack models (Martin et al., 1994). More detailed future simulations of the snow cover using climate change scenarios as input have emerged recently (e.g. Lopez Moreno et al., 2009, 2011; Bavay et al., 2009, 2013; Lafaysse et al., 2014; Piazza et al., 2014), allowing better quantifica- tion of the projected changes. In addition to intuitive consequences of warming such as wetting and a strong decrease of snow cover area and height, these simulations suggest other important effects, such as an increase of heavy snowfall at high altitude or a much narrower snowmelt discharge peak in spring. However, great difficulties still remain, meaning that prognoses regarding snow evolution are still debated (Räisänen, 2008); the main obstacle in many impact studies pertains to the robustness of the downscaling and debiasing of large-scale atmospheric variables from regional or global climate models (GCM) to the mountain environment, featuring complex topography and, in particular, a wider altitude range than in the topography resolved in GCMs (Rousselot et al., 2012; Bavay et al., 2009, 2013; Lafaysse et al., 2014; Steger et al., 2013). To evaluate the potential impact of global change on snow conditions in the French Alps for the forthcoming decades through numerical simulations on relevant spatial scales, Rousselot et al. (2012) have developed statistical adaptation techniques. Specifically, an analogue method has been applied to regional climate model predictors so as to provide complete, physically consistent time series of meteorological variables which are needed for physically based snowpack modelling.

Among the geomorphic processes controlled by snow and meteorological variables, and, on longer timescales, by climate, natural avalanche activity strongly impacts mountain communities through the related risk for humans and infrastructures. Hence, the possible occurrence of catastrophic events (e.g. Ammann and Bebi, 2000) under ongoing climate change requires accurate adaptation strategies (Richard et al., 2010). However, how to quantify the impact of the recent changes in mountain climate on natural avalanche activity and its future evolution in terms of possible modifications of the frequency and intensity of both ordinary and extreme events remains a rather open question (Keiler et al., 2010; IPCC, 2012).

Evidence of significant changes in real avalanche data series over the last 60 years has been provided over the last years, notably in the French Alps (Eckert et al., 2010a, b, 2013), with clear links to snow and meteorological changes (Castebrunet et al., 2012) and their altitudinal control (Lavigne et al., 2012, 2014). The question of observed changes in different types of avalanche activity (wet/dry and or with/without a powder component) has been tackled even more recently (Pielmeier et al., 2013; Eckert et al., 2013). Regarding future evolution for the 21 st century, to our knowledge, the only existing results are those of Martin et al. (2001) and Lazar and Williams (2008). These studies both suggested an ongoing increase in the proportion of wet-snow avalanches as compared to dry-snow avalanches, and a shift in their timing. This is consistent with already existing field observations of snow cover wetting on a small scale and its link with wet-snow release susceptibility (Mitterer et al., 2011), but without a clear quantification of how this correlates to the amplitude of change in total avalanche activity. 
On the basis of these works, the current study aims at producing a detailed description of projected changes of snowpack characteristics expected in the French Alps in the mid and late 21 st century, including latitudinal, altitudinal and seasonal gradients and under three greenhouse gas (GHG) emissions scenarios. These results, expanding on those of Rousselot et al. (2012), are then used to feed statistical models developed by Castebrunet et al. (2012) to link avalanche activity and the snow and meteorological data produced by the SAFRAN-Crocus-MEPRA (Système d'Analyse Fournissant des Renseignements Adaptés à la Nivologie-CrocusModèle Expert d'aide à la Prévision du Risque d'Avalanche) model chain (see below). Hence, future changes in avalanche activity on annual/seasonal timescales are compared to the 1960-1990 control period on the basis of natural, actually observed avalanche activity and simple but robust statistical relations.

\section{Data and methods}

\subsection{Past meteorological, snow and avalanche data on the massif scale}

The primary data used in this study consists of daily observed and simulated past snow and meteorological data and avalanche counts over the French Alps on the geographical scale of the 23 massifs of the French Alps used for operational avalanche forecasting (Fig. 1). The surface area of each massif is about $500 \mathrm{~km}^{2}$, and the key assumption regarding snow and meteorological numerical simulations is their spatial homogeneity, i.e. within each massif meteorological and snowpack properties are assumed to depend only on altitude, slope and aspect (Durand et al., 1999).

Daily observed avalanche data come from the "Enquête Permanente sur les Avalanches" (EPA) which describes the avalanche events on approximately 3900 designated paths in the French Alps and Pyrenees since the beginning of the 20st century (Mougin, 1922). The most common use for EPA data is hazard (e.g. Ancey et al., 2004; Eckert et al., 2007a) and risk (e.g. Eckert et al., 2009) assessment on the path scale. However, the EPA is also well suited for large-scale studies on relations with snow and meteorological covariates (Jomelli et al., 2007), major avalanche episodes (Eckert et al., 2010c) and spatial variations in avalanche activity (Eckert et al., 2007b). For climate studies, the major advantages of the EPA are the long time span of the available data series in the context of a well-structured observation network, giving a relatively accurate view of the spatio-temporal fluctuations of natural avalanche activity in France over the last century. Various quantitative (run out elevations, deposit volumes, etc.) and qualitative (flow regime, snow quality, etc.) data (Jamard et al., 2002) are recorded. Sources of uncertainties and systematic errors in the estimation of certain variables are nu-

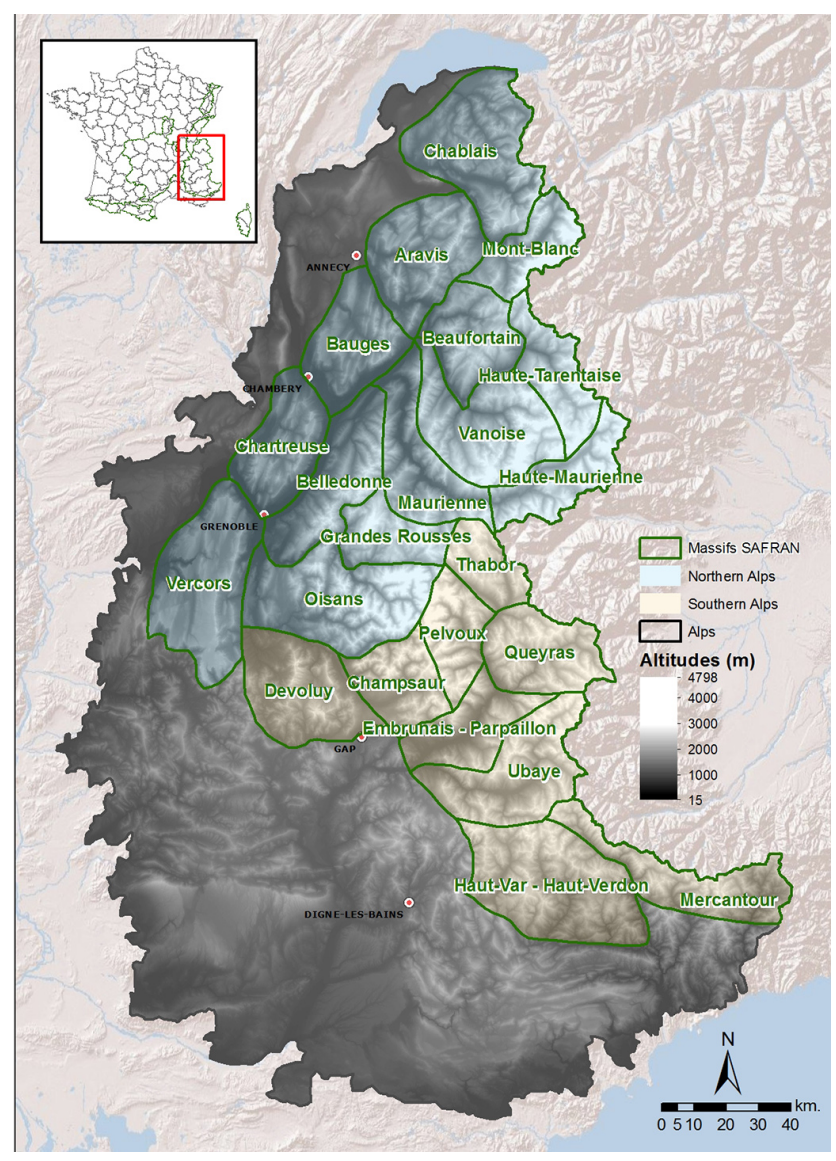

Figure 1. Area studied. Within the SAFRAN model, the French Alps are divided into 23 massifs (source: H. François, IRSTEA, Institut de recherche en sciences et technologies pour l'environnement et l'agriculture).

merous and detailed in previous studies (e.g. Eckert et al., 2010c; Castebrunet et al., 2012).

In this study, among all the available information, only avalanche counts, which represents the most natural variable to describe the frequency of the phenomenon, are considered. In this case, the predominant source of error to be considered is unrecorded events. Locally, the quality of the records depends to a large extent on careful data recording by local observers (mostly forestry rangers). However, once the avalanche counts are aggregated on the massif scale, these local heterogeneities are smoothed, making the automatic detection of abnormally low records very difficult. For instance, there does not exist any local series which can be considered fully error-free with certainty. As a consequence, homogenization methods (e.g. Caussinus and Mestre, 2004) are difficult to implement and were not used in this study. This must be kept in mind when interpreting results. Also, it is generally admitted that the EPA record underestimates avalanche activity at high elevations because human observations concern mainly paths visible from valley floors. This is another 
potential source of bias to be addressed while exploiting the extremely valuable information conveyed by EPA records.

Daily snow and meteorological conditions consist of outputs from a reanalysis of meteorological and snow conditions computed using the SAFRAN-Crocus-MEPRA model chain (SCM; Durand et al., 1999, 2009a, b). The meteorological analysis is performed on the scale of the massifs shown in Fig. 1, for which meteorological conditions are assumed to be homogeneous but to vary with altitude. Durand et al. (2009a, b) performed a complete reanalysis of meteorological and snow conditions with SCM using 44 years of analysed large-scale atmospheric model data from the 40-year European Centre for Medium-Range Weather Forecast (ECMWF) reanalysis (ERA-40) project (Uppala et al., 2004), together with meteorological observations including numerous mountain stations. This reanalysis, complemented for several years beyond the end date of the ERA-40 data set using large-scale meteorological fields from Météo-France operational numerical weather prediction models, covers the period from 1958 to 2009 and is referred to as the model run. For the present study, the variables given below were used, similar to those described by Castebrunet et al. (2012). They concern the 23 alpine massifs (Fig. 1) for three elevations (low, mid and high - 1800, 2400, and $3000 \mathrm{~m}$ a.s.l.), leading to 57 variables in total:

- Daily cumulated precipitation (rain and snow), temperature (daily minimum, maximum, and mean), maximum daily wind speed and the associated direction (SAFRAN outputs).

- For the four main aspects (northern, eastern, southern, and western) and $40^{\circ}$ slope, the snow depth, the thickness of surface wet snow and the thickness of recent surface dry snow. These variables are derived from outputs of the detailed snowpack model Crocus fed by SAFRAN meteorological conditions (Brun et al., 1992). The thickness of surface wet snow is defined, starting from the top of the snowpack downwards, as the sum of the vertical component of the thickness of the contiguous wet-snow layers characterized by a liquid water content greater than $0.5 \%$ by volume. The thickness of the recent surface dry snow is defined as the vertical distance between the snowpack surface and the deepest snow layer characterized by a dendricity greater than 0.25 . The threshold expressed in terms of dendricity (Brun et al., 1992) ensures that the considered snow layer still features characteristics of precipitation particles or decomposed fragments (Fierz et al., 2009), and it accounts for the impact of snow metamorphism on snow layers in a more consistent way than relying only on snow age because the rate of transformation of snow properties strongly depends on temperature, temperature gradient and the occurrence of wet-snow conditions, which are explicitly considered in Crocus and thus captured in our definition of recent surface dry snow.

- The MEPRA natural snowpack instability index, which is a proxy for avalanche hazard (Giraud, 1993; Durand et al., 1999), is a diagnostic tool assessing snowpack stability based on Crocus-simulated snow stratigraphy. MEPRA outputs, which are computed within each massif for each slope, altitude and aspect class, are aggregated on the massif scale, thereby providing a single scalar value for a given date. This aggregated MEPRA index, called hereafter MI, varies between 0 and 8 ( 8 being the higher instability level) dependent on both the SAFRAN-Crocus inputs and the characteristics of each massif. The MI should be viewed as a synthetic combination of SAFRAN-Crocus snow and meteorological data relevant to estimate potential avalanche release rather than a true measure of avalanche activity. It is important to keep in mind that the MI is used in an operational context to help the forecasting of potential snowpack instability and so has to be sensitive to snow and meteorological conditions especially when avalanche hazard is important. On the other hand, this index is less sensitive in the case of instability being lower, leading to sporadic events on the massif scale, as discussed in Castebrunet et al. (2012).

\subsection{Relating avalanche activity to snowpack and meteorological covariates through regression models on large spatio-temporal scales}

Castebrunet et al. (2012) proposed a time-implicit approach for the detection of abnormal years and low-frequency trends in various indicators of natural avalanche occurrence: EPA counts, MEPRA index and a composite index combining these two measures (see below). The best explanatory snow and meteorological covariates were selected with a stepwise regression (e.g. Saporta, 2006), i.e. a variable selection procedure for linear models in which the set of predictive variables is retained by an automatic sequence of Fisher $F$ tests. The regression model obtained relates the series $y_{t}$ of avalanche activity indicators to $P$ selected standardized explanatory variables $X_{j t}^{\text {norm }}$ such that

$y_{t}=\sum_{j=1}^{p} X_{j t}^{\mathrm{norm}} \beta_{j}+\varepsilon_{t}$,

with $\beta_{j}$, the weighting coefficient, representing the contribution of each predictive variable retained to the fluctuations of avalanche activity, and $\varepsilon_{t}$ being the residual activity not predicted by the model. The values of $\varepsilon_{t}$ are modelled as independent and identically distributed realizations of a centred Gaussian random number with standard deviation $\sigma$. The function $\sum_{j=1}^{p} X_{j t}^{\text {norm }} \beta_{j}$, seen as a time series, shows temporal 
fluctuations that are clearly related to the temporal fluctuations of the covariates, hence providing a better understanding of the response of avalanche activity to changes in its most important drivers than a direct time series analysis of the $y_{t}$ series.

Rather than focusing on daily counts on the massif scale, Castebrunet et al. (2012) considered larger spatio-temporal scales. Annual (15 December to 15 June) and seasonal (winter and spring) series of anomalies were calculated both for the entire French Alps and for two sub-regions referred to as the northern French Alp, and the southern French Alps (Fig. 1). Winter and spring seasons were defined as the 15 December to 14 March and 15 March to 15 June subperiods. On these scales, regression models between the SCM-ERA40 outputs and avalanche activity cover the period 1958-2009. Analysis and validation showed that they were able to represent both high and low peaks and lowfrequency trends, indicating a clear statistical relation between the fluctuations of avalanche activity and those of the selected covariates. This was a rather surprising result given that the avalanche release process is a strongly discontinuous response to meteorological patterns and changes in snowpack characteristics, so that a weaker and/or nonlinear relation was expected for sub-seasonal and seasonal scales. It appeared that the explanation may be that averaging over large areas and relatively long periods smoothes the signal, switching from meteorological and snowpack control on the daily scale to seasonal characteristics of the latter, making it possible to capture the predominant factors for the long-term interannual evolution in a more climatological sense with simple statistical regression models. On the other hand, the approach loses the information related to the succession of short-term meteorological situations (e.g. multiday intense snowfall) interacting with a few massifs, except from the perspective of their contribution to the annual/seasonal mean. Hence, the approach is adapted to investigate seasons of high/lowavalanche activity over large areas but not for the more localized 1-7-day episodes of highest activity. See Sect. 4 for further discussion of spatio-temporal scales.

Castebrunet et al. (2012) also showed that good correlations exist between EPA avalanche counts and the MEPRA index (MI) during cold winter periods even if the MI may better represent such conditions due to avalanche counts missed due to bad weather. In contrast, it was found that the MI often fails to capture avalanche activity linked to wetsnow conditions during spring and, more generally, localized or short avalanche events. To limit these drawbacks/biases, a composite index referred to as CI was proposed to combine EPA and MI avalanche activity indicators and better represent the overall natural activity. It is computed using the annual anomalies of the instability index $\operatorname{MEPRA}_{t}^{\text {norm }}$ and avalanche counts $\mathrm{EPA}_{t}^{\text {norm }}$, and the correlation coefficient $\rho_{t}$ of their daily values during the year/season:

$\mathrm{CI}_{t}=\frac{1}{3}\left(0.5 \mathrm{EPA}_{t}^{\mathrm{norm}}+0.5 \mathrm{MEPRA}_{t}^{\mathrm{norm}}+\rho_{t}\right)$.

It gives equal weight to EPA counts and the MI and favours or disfavours years or seasons where both index are consistent or unconsistent, and vice versa. Standardization is used to spread the values over a $[-2,2]$ range similar to the one corresponding to the explanatory variables. Finally, while the $\mathrm{CI}$ is primarily computed on the massif scale, obtaining spatially averaged time series is straightforward, assuming similar weights for all massifs.

Based on this work, we assume in this study that the CI is the best indicator of natural avalanche activity and we base the assessment of future changes in avalanche activity on it for the same nine spatio-temporal scales (three regions and three periods; see Sect. 3). We will, however, check and discuss the consistency of the patterns we highlight with the annual/seasonal changes using the MI, which can be computed for the future from the simulations of future snow characteristics, in contrast to EPA data, which by their nature are only available for past years. In addition to the work already reported by Castebrunet et al. (2012), we developed new regression models with the same stepwise selection methodology but considering only the period 1961-1990 (instead of 1958-2009) of the simulation SCM-ERA40. This was found necessary for (i) dealing with the control period used for the climate projections (see Sect. 2.3), and (ii) enlarging the temporal gap between the reference period 1961-1990 and the 2020-2050 period.

The obtained nine new CI regression models are summarized in Tables 1-3. All determination coefficients are very good (higher than 0.7 ), which illustrates the relevance of explaining avalanche activity with a few (from one to nine) snowpack and meteorological covariates. On the largest scale considered (the entire French Alps and the whole avalanche year, Table 1), the CI model (determination coefficient $R^{2}=0.91$ ) includes four snow variables, all of which relate to northern slopes. Only snow depth at $2400 \mathrm{~m}$ has a negative contribution to the avalanche activity indicator CI. The statistical method employed indicates that more variables are required to explain the CI for the northern French Alps (nine), while four are sufficient for the southern French Alps. This difference in variable numbers necessary to explain the year-to-year variability of avalanche activity may be linked to the larger extension of the northern French Alps, which include three massifs characterized by low altitude (under $2500 \mathrm{~m}$ ), making the triggering contexts less homogeneous. The retained variables in the northern French Alps concern different slope orientations (north, east and west) and maximal daily temperatures at mid and high elevations in addition to snowpack characteristics. For the southern French Alps, the CI model includes snow precipitation at $3000 \mathrm{~m}$ and snowpack variables for north and west slopes. 
Table 1. Regression model characteristics for the French Alps (all year, winter and spring periods). For each model, the different variables are those selected by the stepwise regression. For each retained normalized explanatory variable, $X_{j t}^{\text {norm }}, \beta_{j}$ is the corresponding weighting coefficient in the model; $\rho_{j}$ the correlation coefficient between $X_{j t}^{\text {norm }}, \beta_{j}$ and the composite index; and $R^{2}$ the determination coefficient of the model.

\begin{tabular}{|c|c|c|c|}
\hline \multicolumn{4}{|l|}{ French Alps, year } \\
\hline Explanatory variables $j$ & $\beta_{j}$ & $\rho_{j}$ & $R^{2}$ \\
\hline Snow precipitation $(1800 \mathrm{~m})$ & 0.09 & 0.84 & 0.91 \\
\hline Thickness of wet snow (1800 m, north) & 0.06 & 0.84 & \\
\hline Snow depth (2400 m, north) & -0.13 & -0.70 & \\
\hline Thickness of recent surface dry snow (3000 m, north) & 0.12 & 0.89 & \\
\hline \multicolumn{4}{|l|}{ French Alps, winter } \\
\hline Explanatory variables $j$ & $\beta_{j}$ & $\rho_{j}$ & $R^{2}$ \\
\hline Thickness of wet snow (2400 m, north) & 0.09 & 0.23 & 0.82 \\
\hline Thickness of recent surface dry snow (3000 m, east) & 0.34 & 0.85 & \\
\hline Thickness of recent surface dry snow ( $2400 \mathrm{~m}$, west) & -0.19 & -0.80 & \\
\hline \multicolumn{4}{|l|}{ French Alps, spring } \\
\hline Explanatory variables $j$ & $\beta_{j}$ & $\rho_{j}$ & $R^{2}$ \\
\hline Thickness of wet snow ( $2400 \mathrm{~m}$, north) & -0.09 & 0.01 & 0.89 \\
\hline Thickness of wet snow ( $2400 \mathrm{~m}$, east) & 0.16 & 0.53 & \\
\hline Thickness of recent surface dry snow ( $3000 \mathrm{~m}$, south) & -0.13 & -0.73 & \\
\hline Thickness of recent surface dry snow ( $2400 \mathrm{~m}$, west) & 0.26 & 0.81 & \\
\hline Snow depth $(3000 \mathrm{~m}$, west $)$ & -0.07 & -0.45 & \\
\hline
\end{tabular}

Regarding the winter period, CI models for the three regions are characterized by a limited number of covariates related to thickness of snow (1 to 3) and by the predominant contribution of the thickness of recent surface dry snow at $3000 \mathrm{~m}$ for eastern slopes (marginal correlation with the composite index $\rho_{j}>0.8$ ). This highlights that this season is dominated by fresh dry-snow avalanches. While for the northern French Alps the statistical model only includes the thickness of recent surface dry snow, the thickness of wet snow for northern slopes also contributes to the statistical models on the scales of both the entire French Alps and southern French Alps.

For the spring period, more variables are required to adequately explain the annual fluctuations of the CI (two to five). They concern snowpack characteristics, mainly at mid $(2400 \mathrm{~m})$ and high $(3000 \mathrm{~m})$ elevations. For instance, two of four variables are thicknesses of wet snow for the northern French Alps, which is consistent with the fact that spring avalanches are mainly wet-snow avalanches. Notably, this is not the case for the southern French Alps, but the snow depth on south-facing slopes is included in the model and may play a similar role.

The efficiency and robustness of the nine regression models have been evaluated and checked on the 30-year calibration sample using a leave-one-out validation scheme. In the latter, each "data point" (year) is in turn removed from the calibration sample; the model is fitted without the removed year, which is then predicted with the fitted model. Figure 2 shows the predictive performance of three statistical models corresponding to the different regions/time periods studied. Nearly all predicted values fall in the $95 \%$ confidence intervals around the data (the traditional \pm two standard deviations in a linear regression), and predictions obtained with this validation procedure are very close to the ones obtained when the whole data set is used for calibration.

Table 4 quantifies and generalizes these statements, showing that, for all the models, nearly "perfect" success rates are obtained in calibration, i.e. around $95 \%$ of the predictions falling in the $95 \%$ confidence intervals around the data. In the leave-one-out cross-validation procedure, success rates are, unsurprisingly, a bit lower, but remain as high as $\sim 90 \%$, showing that in each region/period, the model is able to predict correctly nearly all observations without the data corresponding to each observation. Again, the slightly lower prediction rates for the northern French Alps (full year and winter) may be linked to their large extension and, hence, heterogeneity. However, this may also be fortuitous, since the differences between prediction rates between zones/periods are quite small. Anyhow, these results can be considered very satisfactory considering the crudeness of the statistical modelling approach employed. They give confidence in the fitted relationships between avalanche activity and meteorological and snowpack conditions, and in their ability, despite their arguable oversimplification, to roughly reproduce different 
Table 2. Regression model characteristics for the northern French Alps (all year, winter and spring periods). For each retained explanatory variable $X_{j t}^{\text {norm }}, \beta_{j}$ is the corresponding weighting coefficient in the model; $\rho_{j}$ is the correlation coefficient between $X_{j t}^{\text {norm }}, \beta_{j}$ and the composite index; and $R^{2}$ is the determination coefficient of the model.

\begin{tabular}{|c|c|c|c|}
\hline \multicolumn{4}{|l|}{ Northern French Alps, year } \\
\hline Explanatory variables $j$ & $\beta_{j}$ & $\rho_{j}$ & $R^{2}$ \\
\hline$T_{\max }(2400 \mathrm{~m})$ & -0.15 & 0.32 & 0.97 \\
\hline$T_{\max }(3000 \mathrm{~m})$ & 0.19 & -0.19 & \\
\hline Thickness of wet snow (1800 m, north) & -0.05 & -0.85 & \\
\hline Thickness of recent surface dry snow (1800 m, north) & 0.43 & 0.87 & \\
\hline Thickness of recent surface dry snow (3000 m, north) & -0.27 & -0.90 & \\
\hline Thickness of wet snow ( $2400 \mathrm{~m}$, east) & 0.17 & 0.61 & \\
\hline Thickness of recent surface dry snow (3000 m, east) & 0.43 & 0.90 & \\
\hline Thickness of recent surface dry snow (1800 m, west) & -0.34 & -0.87 & \\
\hline Thickness of wet snow ( $2400 \mathrm{~m}$, west) & -0.11 & -0.50 & \\
\hline \multicolumn{4}{|l|}{ Northern French Alps, winter } \\
\hline Explanatory variables $j$ & $\beta_{j}$ & $\rho_{j}$ & $R^{2}$ \\
\hline Thickness of recent surface dry snow (3000 m, east) & 0.22 & 0.85 & 0.71 \\
\hline \multicolumn{4}{|l|}{ Northern French Alps, spring } \\
\hline Explanatory variables $j$ & $\beta_{j}$ & $\rho_{j}$ & $R^{2}$ \\
\hline Thickness of recent surface dry snow ( $2400 \mathrm{~m}$, north) & 0.35 & 0.78 & 0.80 \\
\hline Thickness of wet snow (2400 m, east) & 0.26 & 0.45 & \\
\hline Thickness of wet snow (2400 m, west) & -0.20 & -0.33 & \\
\hline Thickness of recent surface dry snow (3000 m, west) & -0.21 & -0.72 & \\
\hline
\end{tabular}

types of avalanche episode contexts, at least for the climate of the reference period (see Sect. 4 for discussion of their validity under a future climate).

\subsection{Modelling climate, snowpack characteristics and avalanche activity in the future}

In order to carry out projections of the impact of climate change on snow conditions and avalanche activity in the French Alps, the model chain SCM was run using, as input, a reanalysis of meteorological conditions spanning the period 1960-1990 and synoptic-scale meteorological variables from the regional climate model (RCM) ALADIN-climateV4 (Aire Limitée Adaptation dynamique Développement InterNational) (Rousselot et al., 2012), run at $12 \mathrm{~km}$ resolution.

Three running periods have been considered: the reference period (1961-1990) and two future periods in the mid and late 21st century (2021-2050 and 2071-2100) according to three 4th IPCC (IPCC, 2007) emission scenarios (IPCC Special Report on Emissions Scenarios (SRES) B1, A1B and A2):

- The A1B scenario describes a future world with rapid, globalized economic growth, the development of new, more efficient technologies, and a global population increase until the mid century with a decline thereafter.
- The A2 scenario assumes regionally heterogeneous economic and technological development throughout the world and a continuously increasing population. This is one of the most greenhouse-gas(GHG)-emissive IPCC scenarios.

- The B1 scenario assumes similar evolution of the global population to that in $\mathrm{A} 1 \mathrm{~B}$, but with an economy dominated by services and information activities and the use of clean technologies. This scenario is the leastemissive one, with GHG emissions that are stabilized before the end of the century.

Since A1B scenario is the closest to the 2050 forecasts of the International Energy Agency, we mainly focus on this scenario in this work, but the three of them were tested and the results are briefly reported in Sect. 3.

The ALADIN RCM boundary conditions were provided by the global ARPEGE-climate-V4 (Action de Recherche Petite Échelle Grande Échelle) GCM (Deque and Somot, 2007), running with a variable horizontal resolution of about $50 \mathrm{~km}$ over Europe. The sea surface temperature used for coupling ALADIN to ARPEGE originates from previous coarser resolution runs of ARPEGE. The reference period (called EM6) is a continuous ALADIN simulation between 1961 and 1990, whereas both future climatic periods, 
a) Whole French Alps, full year

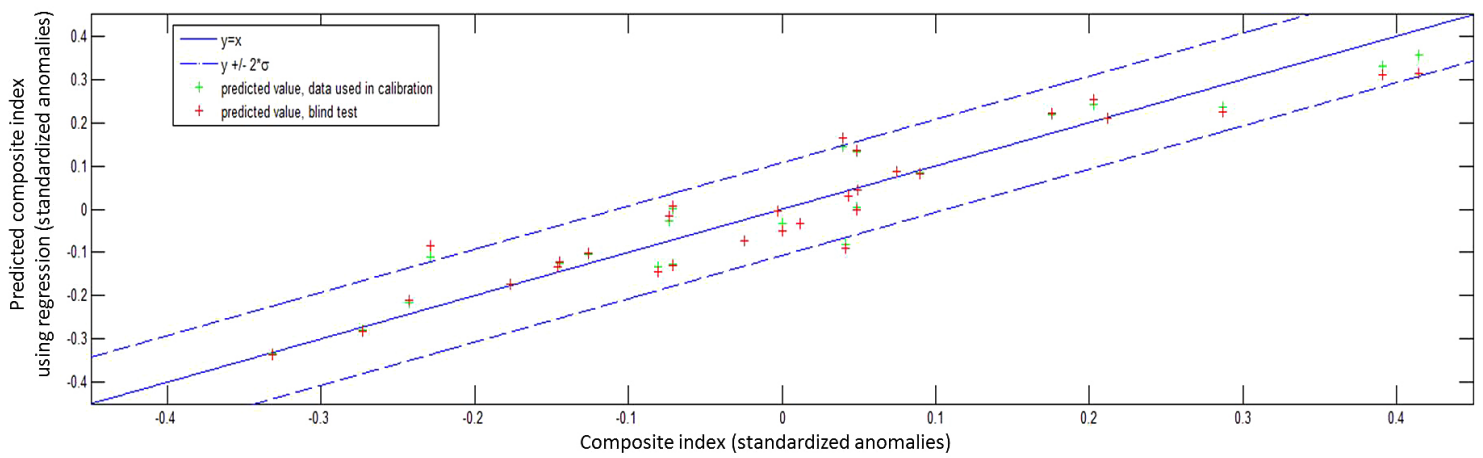

b) Northern French Alps, winter

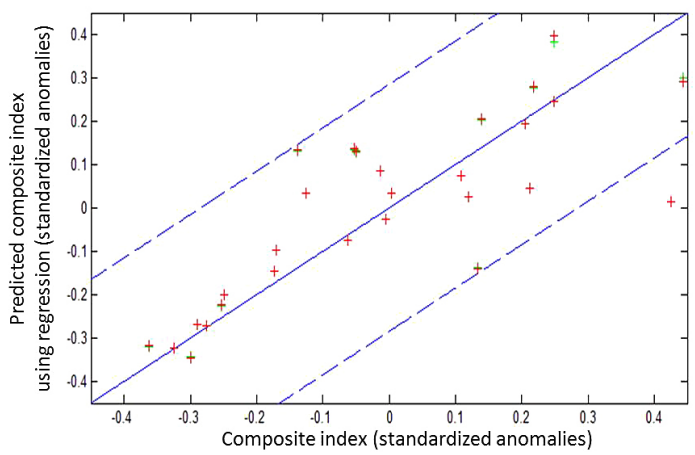

c) Southern French Alps, spring

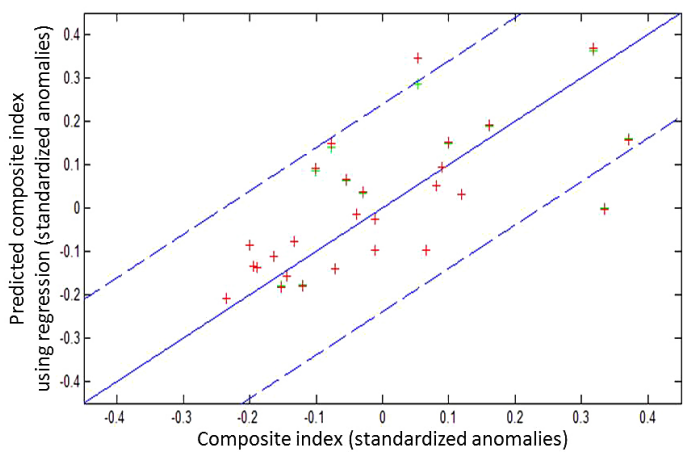

Figure 2. Cross-validation of the composite index regression model for the reference period: entire French Alps for the full avalanche year (a), northern French Alps in the winter season (b) and southern French Alps in the spring season (c). In each panel, the predictive performance is assessed with/without (leave-one-out scheme) each pseudo-observation. To represent predictive uncertainty around the first bisector, the classical bandwidth of \pm two standard deviations is included.

2021-2050 (called EM7) and 2071-2100 (called EM9), are simulations consisting of 30 independent yearly simulations.

The method implemented here to compute the impact of climate change on meteorological conditions in the SAFRAN massifs representing the French Alps derives from Rousselot et al. (2012) with significant differences. Indeed, Rousselot et al. (2012) carried out nearestneighbour research of similar meteorological situations (analogue method) from the synoptic-scale field output from ALADIN for the present and future climate and associated it with the corresponding meteorological forcing for each date from the SAFRAN reanalysis (Durand et al., 2009a, b) to build the meteorological forcing data set (referred to as the DATE method). This method has the benefit of following the large-scale chronology of meteorological conditions from the ALADIN RCM, but it introduces discontinuities in meteorological variables every day between two analogue days. In this study, an alternative approach was taken, fully relying on the chronology of meteorological conditions from the reference period 1960-1990 and applying corrections to this continuous time series based on a quantile-mapping method (Deque, 2007).
Firstly, for each simulation and each ALADIN grid point, meteorological daily fields are compared with daily data from the ECMWF ERA-40 reanalysis (Uppala et al., 2004), and a date with analogue weather conditions is identified through an appropriate distance. The series of analogue dates is then used to extract corresponding meteorological data from the SCM-ERA40 meteorological reanalysis (Durand et al., 2009a) that we call EMx $x_{\text {DATE }}^{\mathrm{CS}}$, with $x=6,7$ or 9 and CS being the SRES scenario, namely A1B, A2 or B1. Percentiles of each meteorological variable for each scenario and time period are then computed based on each collection of SCM-ERA40 data for the corresponding selected dates. Percentiles for the same variables but for the entire SCM-ERA40 time series were also computed. For consistency, the SCM-ERA40 data series used were limited to the 1960-1990 period, both for the data search and for the percentile calculation. These percentiles (at rank $\alpha$ ) are denoted as $\mathrm{q}_{\alpha}\left(\mathrm{EMx}_{\mathrm{DATE}}^{\mathrm{SC}}\right)$ and $\mathrm{q}_{\alpha}\left(\mathrm{SCM}^{\mathrm{ERA} 40}\right)$, respectively, and are used to produce ranked differences, at the same $\alpha$ percentile value, between the different RCM projections (as a series of dates) and the statistics of meteorological variables into the SCM-ERA40 record. 
Table 3. Regression model characteristics for the southern French Alps (all year, winter and spring periods). For each retained explanatory variables $X_{j t}^{\text {norm }}, \beta_{j}$ is the corresponding weighting coefficient in the model; $\rho_{j}$ is the correlation coefficient between $X_{j t}^{\text {norm }}, \beta_{j}$ and the composite index; and $R^{2}$ is the determination coefficient of the model.

\begin{tabular}{|c|c|c|c|}
\hline \multicolumn{4}{|l|}{ Southern French Alps, year } \\
\hline Explanatory variables $j$ & $\beta_{j}$ & $\rho_{j}$ & $R^{2}$ \\
\hline Snow precipitation $(3000 \mathrm{~m})$ & -0.08 & -0.55 & \multirow{4}{*}{0.91} \\
\hline Thickness of wet snow (1800 m, north) & 0.14 & 0.86 & \\
\hline Snow depth (2400 m, north) & -0.09 & -0.65 & \\
\hline Thickness of recent surface dry snow (3000 m, west) & 0.22 & 0.85 & \\
\hline \multicolumn{4}{|l|}{ Southern French Alps, winter } \\
\hline Explanatory variables $j$ & $\beta_{j}$ & $\rho_{j}$ & $R^{2}$ \\
\hline Thickness of wet snow (2400 m, north) & 0.11 & 0.23 & \multirow{3}{*}{0.86} \\
\hline Thickness of recent surface dry snow ( $2400 \mathrm{~m}$, east) & -0.20 & -0.80 & \\
\hline Thickness of recent surface dry snow ( $3000 \mathrm{~m}$, west) & 0.39 & 0.87 & \\
\hline \multicolumn{4}{|l|}{ Southern French Alps, spring } \\
\hline Explanatory variables $j$ & $\beta_{j}$ & $\rho_{j}$ & $R^{2}$ \\
\hline Thickness of recent surface dry snow ( $2400 \mathrm{~m}$, east) & 0.13 & 0.83 & \multirow{2}{*}{0.77} \\
\hline Snow depth (1800 m, south) & 0.08 & 0.71 & \\
\hline
\end{tabular}

Table 4. Predictive performance of CI regression models in cross validation, where each year is included or not in the calibration sample. The success rate corresponds to the percentage of prediction falling into the $95 \%$ confidence interval around the data.

\begin{tabular}{lcc}
\hline & $\begin{array}{c}\text { Prediction success } \\
\text { rate }(\%), \text { calibration }\end{array}$ & $\begin{array}{c}\text { Prediction success } \\
\text { rate }(\%), \text { validation }\end{array}$ \\
\hline French Alps, whole year & 93 & 90 \\
French Alps, winter & 97 & 93 \\
French Alps, spring & 97 & 93 \\
Northern French Alps, whole year & 93 & 87 \\
Northern French Alps, winter & 97 & 87 \\
Northern French Alps, spring & 93 & 93 \\
Southern French Alps, whole year & 97 & 90 \\
Southern French Alps, winter & 93 & 93 \\
Southern French Alps, spring & 97 & 93 \\
\hline
\end{tabular}

The differences between RCM outputs and SCM-ERA40 reanalysis can be split in two components:

- the "intrinsic" model bias, i.e. the difference between the percentiles of the control period simulation EM6DATE and the SCM-ERA40 time series SCM ${ }^{\text {ERA40, }}$ which is due to the fact that the ALADIN model in its EM6 run does not match the SCM-ERA40 density function:

$$
\delta_{\text {model }}=\left|q_{\alpha}\left(\mathrm{EM}_{\mathrm{DATE}}\right)-q_{\alpha}\left(\mathrm{SCM}^{\mathrm{ERA} 40}\right)\right| ;
$$

- the difference linked to the simulated climate change signal, i.e. the difference between the percentiles of the future period simulation and the SCM-ERA40 simula-

$$
\begin{aligned}
& \text { tion } \mathrm{SCM}^{\mathrm{ERA} 40}: \\
& \delta_{\mathrm{CC}}=\left|q_{\alpha}\left(\mathrm{EM} 7,9_{\mathrm{DATE}}^{\mathrm{SC}}\right)-q_{\alpha}\left(\mathrm{SCM}^{\mathrm{ERA} 40}\right)\right| .
\end{aligned}
$$

Both corrections were applied to SAFRAN meteorological variables of the entire time series, leading to meteorological fields called EMx $\mathrm{CENT}_{\mathrm{CS}}^{\mathrm{CS}}$ and represented as follows:

$\mathrm{EM} 7,9_{\mathrm{CENT}}^{\mathrm{CS}}=\mathrm{SCM}^{\mathrm{ERA} 40}+\delta_{\mathrm{CC}}-\delta_{\text {model }}$.

In other words, the technique employed consists of adding a correction representative of the difference between the ALADIN behaviour in the present and the changed climatic conditions to the meteorological reanalysis SCM-ERA40. This correction takes into account the potential deficiencies of the 
EM6DATE run when compared to the SCM-ERA40 climatology, and we postulate that these modelling errors are the same in the climate change runs EM7, $9{ }_{\mathrm{DATE}}^{\mathrm{CS}}$. This convenient assumption has been widely used in previous studies and is discussed for instance in Wilby et al. (1998) and Deque (2007). In the present work, we note that the magnitude of the $\delta_{\text {model }}$ correction is small for several variables (Rousselot et al., 2012).

The meteorological fields EM7 ${ }_{\text {CENT }}^{\text {CS }}$ and EM9 ${ }_{\text {CENT }}^{\text {CS }}$ were then used as inputs to drive the detailed snowpack model Crocus and, subsequently, to compute the MEPRA index for the two considered 30-year future periods and under the three different SRES scenarios considered. Simulated SAFRAN and Crocus data from the daily series on the massif scale were used to derive anomaly series on the nine larger spatiotemporal scales corresponding to those studied for the reference period.

Finally, the nine CI regression models obtained over the reference period were fed with these projected snow and meteorological data (after suitable standardization), using appropriate weighting coefficients (Tables 1-3) and leading to projected values of the avalanche activity index CI for the two future periods of annual and seasonal avalanche activity indexes for the nine regions/seasons considered. For example, Fig. 3 presents the distribution of annual and seasonal values of the CI regression model during the reference period and the two time periods considered in the future on the scale of the entire French Alps. For the reference period, simulated values are shown as well as a reasonably smoothed approximation of their density function from a semi-parametric interpolation of the pseudo-observations with a Gaussian kernel smoother. For the future period, for clarity, only the smoothed density functions are displayed.

\subsection{Quantitative assessment of changes}

Quantitative assessment of changes between the reference period (1961-1990) and the two future periods considered (2020-2050 and 2070-2100) was made for a selection of snow and meteorological variables at different elevations and expositions (Table 5) for the CI (Table 6) and for the MEPRA index MI (Table 7).

More precisely, we computed normalized differences in means Diff ${ }^{\text {means }}$ (differences between interannual means respectively mean $\left(X_{t}\right)$ and mean $\left(Y_{t}\right)$ where $X_{t}$ and $Y_{t}$ are the two considered annual (or seasonal) samples) divided by a surrogate of the variability range as

$\operatorname{Diff}^{\text {means }}=\frac{\operatorname{mean}\left(Y_{t}\right)-\operatorname{mean}\left(X_{t}\right)}{\max \left(X_{t}\right)-\min \left(X_{t}\right)}$

and variance ratios as

$\operatorname{Diff}^{\mathrm{var}}=\frac{\operatorname{var}\left(Y_{t}\right)}{\operatorname{var}\left(X_{t}\right)}$.
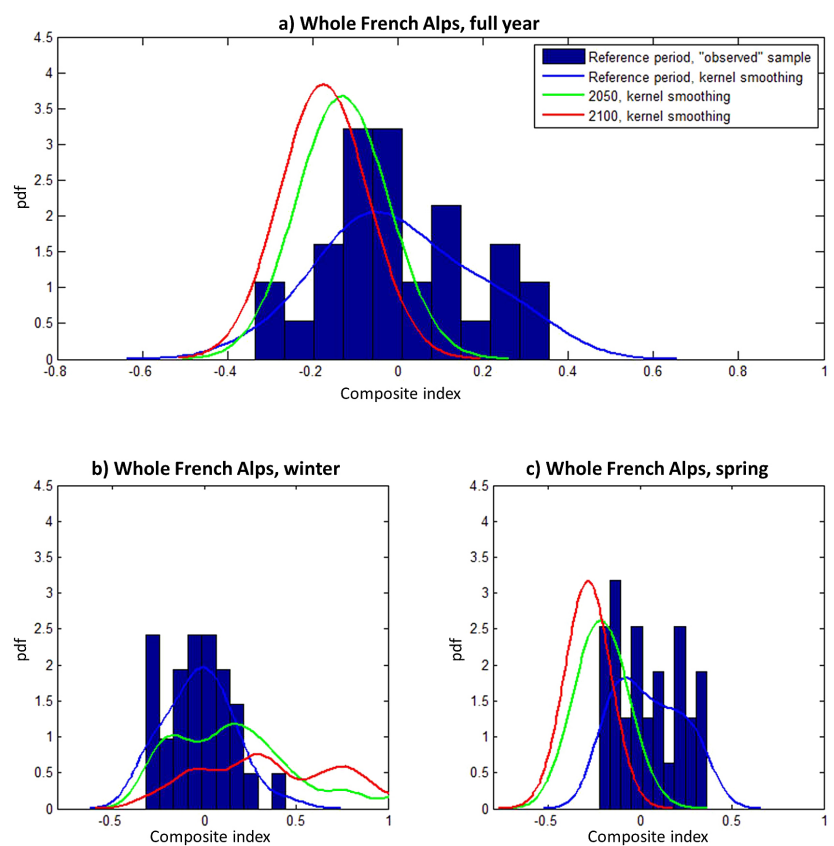

Figure 3. Probability density functions of the annual and seasonal means of the CI regression model over the reference period and in 2020-2050 and 2070-2100. The entire French Alps are considered, during the full avalanche year (a) and during the winter (b) and spring (c) subperiods.

Each climate projection scenario corresponds to 30 years of simulation only, which implies that the significance of changes has to be tested thoroughly as follows:

- The significance of differences between future and reference samples is tested using the KolmogorovSmirnov test.

- The significance of the difference in mean and variance is tested using Fisher and Student tests.

According to the statistical theory, we applied Fisher and Student tests only for $X_{t}$ samples for which the normality tested using the Shapiro-Wilk test was not rejected at the 0.05 significance level. Due to the fact that we have only samples of 30 values and that we are considering annual/seasonal means, the normality assumption was indeed acceptable most of the time, even for asymmetric variables such as snow depths which are generally not Gaussian.

Similarly, according to its theoretical setting, the Student test for means was applied only when the assumption of nonsignificant differences in variances between the two considered $X_{t}$ and $Y_{t}$ samples could not be rejected. Since variances between considered samples were often significantly different, this test could be applied less frequently.

We also assessed the probability of future years/seasons exceeding the mean and high percentiles of the distribution on the reference period. The exceedance probabilities were 
Table 5. Changes in meteorological and snow variables between the reference period and the two future periods for the entire French Alps during the whole year and during the winter and the spring periods. "Ref", 2020-2050 and 2070-2100 correspond, respectively, to the three considered periods - the reference period (1960-1990) and the mid and end of the 21 st century. The probability for a future year to be higher than the reference mean and the 75 and $95 \%$ percentiles of the reference distribution is quantified, as are ratios and differences between the reference variance/mean and the two future variances/means. For the Kolmogorov-Smirnov test, bold values indicate different samples at the 0.05 significance level. When the null hypothesis of similar underlying distributions is not rejected, exceedance probabilities appear in italic, as differences with the reference period may be insignificant. When the assumption of a Gaussian distribution is rejected for at least one of the considered samples, the significance of the variance comparison cannot be tested so that the variance ratios appear in italic. When the assumption of Gaussian distributions with similar variances is rejected for at least one of the considered samples, the significance of the mean comparison cannot be tested so that the mean standardized difference appears in italic. When the significance of variance/mean comparisons could be tested, ratios/standardized differences rejecting the null hypothesis of equality are shown in bold.

\begin{tabular}{|c|c|c|c|c|c|c|c|c|c|c|c|c|c|c|c|}
\hline \multirow[t]{2}{*}{ Whole year } & \multicolumn{3}{|c|}{$\begin{array}{c}\text { Distribution comparison } \\
\text { ( } p \text { value, Kolmogorov-Smirnov test) }\end{array}$} & \multicolumn{3}{|c|}{$\begin{array}{l}\text { Prob. mean } \\
(2020-2050)>\end{array}$} & \multicolumn{3}{|c|}{$\begin{array}{l}\text { Prob. mean } \\
(2070-2100)>\end{array}$} & \multicolumn{3}{|c|}{$\begin{array}{c}\text { Means comparison } \\
\text { (standardized differences) }\end{array}$} & \multicolumn{3}{|c|}{$\begin{array}{l}\text { Variance comparison } \\
\text { (ratios) }\end{array}$} \\
\hline & $\begin{array}{r}\text { Ref/ } \\
2020-2050 \\
\end{array}$ & $\begin{array}{r}\text { Ref/ } \\
2070-2100 \\
\end{array}$ & $\begin{array}{r}2020-2050 / \\
2070-2100\end{array}$ & $\begin{array}{r}\text { Mean } \\
(\mathrm{ref})\end{array}$ & $\begin{array}{r}\mathrm{q} 75 \\
\text { (ref) }\end{array}$ & $\begin{array}{r}\mathrm{q} 95 \\
\text { (ref) }\end{array}$ & $\begin{array}{r}\text { Mean } \\
\text { (ref) }\end{array}$ & $\begin{array}{r}\mathrm{q} 75 \\
(\mathrm{ref})\end{array}$ & $\begin{array}{r}\mathrm{q} 95 \\
\text { (ref) }\end{array}$ & $\begin{array}{r}2020 / 2050 \\
\text { ref }\end{array}$ & $\begin{array}{r}2070 / 2100 \\
\text { ref }\end{array}$ & $\begin{array}{l}2070 / 2100 \\
2020 / 2050\end{array}$ & $\begin{array}{r}2020 / 2050 \\
\text { ref }\end{array}$ & $\begin{array}{r}2070 / 2100 \\
\text { ref }\end{array}$ & $\begin{array}{l}2070 / 2100 \\
2020 / 2050\end{array}$ \\
\hline$T_{\min } 1800 \mathrm{~m}$ & 0.00 & 0.00 & 0.00 & 1 & 1 & 0.75 & 1.00 & 1.00 & 1.00 & 0.76 & 1.53 & 0.77 & 0.99 & 0.85 & 0.86 \\
\hline$T_{\max } 1800 \mathrm{~m}$ & 0.00 & 0.00 & 0.00 & 0.99 & 0.94 & 0.54 & 1.00 & 1.00 & 1.00 & 0.61 & 1.29 & 0.68 & 1.03 & 0.95 & 0.92 \\
\hline$T_{\min } 3000 \mathrm{~m}$ & 0.00 & 0.00 & 0.00 & 1.00 & 0.99 & 0.91 & 1.00 & 1.00 & 1.00 & 0.66 & 1.33 & 0.67 & 0.95 & 0.95 & 1.01 \\
\hline$T_{\max } 3000 \mathrm{~m}$ & 0.00 & 0.00 & 0.00 & 0.99 & 0.96 & 0.59 & 1.00 & 1.00 & 1.00 & 0.57 & 1.15 & 0.59 & 1.01 & 0.88 & 0.86 \\
\hline$P_{\text {tot }} 1800 \mathrm{~m}$ & 0.76 & 0.25 & 0.65 & 0.43 & 0.21 & 0.01 & 0.28 & 0.10 & 0.00 & -0.04 & -0.14 & -0.09 & 0.90 & 0.79 & 0.87 \\
\hline SP $1800 \mathrm{~m}$ & 0.00 & 0.00 & 0.00 & 0.07 & 0.01 & 0.00 & 0.00 & 0.00 & 0.00 & -0.28 & -0.51 & -0.23 & 0.66 & 0.39 & 0.59 \\
\hline$P_{\text {tot }} 3000 \mathrm{~m}$ & 0.94 & 0.14 & 0.41 & 0.41 & 0.20 & 0.01 & 0.26 & 0.09 & 0.00 & -0.05 & -0.13 & -0.08 & 0.88 & 0.77 & 0.87 \\
\hline SP $3000 \mathrm{~m}$ & 0.03 & 0.00 & 0.01 & 0.21 & 0.08 & 0.01 & 0.03 & 0.00 & 0.00 & -0.15 & -0.33 & -0.17 & 0.77 & 0.58 & 0.75 \\
\hline HS (1800 m, north) & 0.00 & 0.00 & 0.00 & 0.00 & 0.00 & 0.00 & 0.00 & 0.00 & 0.00 & -0.52 & -0.65 & -0.14 & 0.16 & 0.05 & 0.30 \\
\hline HS (3000 m, north) & 0.00 & 0.00 & 0.00 & 0.00 & 0.00 & 0.00 & 0.00 & 0.00 & 0.00 & -0.63 & -0.83 & -0.21 & 0.46 & 0.32 & 0.68 \\
\hline HS (1800 m, south) & 0.00 & 0.00 & 0.00 & 0.00 & 0.00 & 0.00 & 0.00 & 0.00 & 0.00 & -0.32 & -0.38 & -0.07 & 0.08 & 0.01 & 0.16 \\
\hline HS ( $3000 \mathrm{~m}$, south) & 0.00 & 0.00 & 0.04 & 0.01 & 0.00 & 0.00 & 0.00 & 0.00 & 0.00 & -0.39 & -0.51 & -0.12 & 0.39 & 0.25 & 0.63 \\
\hline$H_{\mathrm{WS}}(1800 \mathrm{~m}$, north $)$ & 0.00 & 0.00 & 0.00 & 0.00 & 0.00 & 0.00 & 0.00 & 0.00 & 0.00 & -0.41 & -0.56 & -0.14 & 0.25 & 0.11 & 0.44 \\
\hline$H_{\mathrm{WS}}(3000 \mathrm{~m}$, north) & 0.00 & 0.00 & 0.01 & 1.00 & 1.00 & 0.93 & 0.99 & 0.99 & 0.84 & 1.04 & 0.76 & -0.28 & 3.39 & 2.26 & 0.67 \\
\hline$H_{\mathrm{WS}}(1800 \mathrm{~m}$, south $)$ & 0.00 & 0.00 & 0.00 & 0.01 & 0.00 & 0.00 & 0.00 & 0.00 & 0.00 & -0.30 & -0.39 & -0.08 & 0.16 & 0.03 & 0.21 \\
\hline$H_{\mathrm{WS}}(3000 \mathrm{~m}$, south $)$ & 0.01 & 0.84 & 0.02 & 0.77 & 0.57 & 0.25 & 0.54 & 0.27 & 0.04 & 0.21 & 0.02 & -0.19 & 1.55 & 0.97 & 0.62 \\
\hline$H_{\mathrm{DS}}(1800 \mathrm{~m}$, north $)$ & 0.00 & 0.00 & 0.00 & 0.00 & 0.00 & 0.00 & 0.00 & 0.00 & 0.00 & -0.49 & -0.60 & -0.11 & 0.12 & 0.04 & 0.36 \\
\hline$H_{\mathrm{DS}}(3000 \mathrm{~m}$, north $)$ & 0.00 & 0.00 & 0.00 & 0.00 & 0.00 & 0.00 & 0.00 & 0.00 & 0.00 & -0.52 & -0.67 & -0.14 & 0.26 & 0.15 & 0.57 \\
\hline$H_{\mathrm{DS}}(1800 \mathrm{~m}$, south $)$ & 0.00 & 0.00 & 0.00 & 0.00 & 0.00 & 0.00 & 0.00 & 0.00 & 0.00 & -0.44 & -0.54 & -0.10 & 0.12 & 0.04 & 0.37 \\
\hline$H_{\mathrm{DS}}(3000 \mathrm{~m}$, south $)$ & 0.00 & 0.00 & 0.03 & 0.00 & 0.00 & 0.00 & 0.00 & 0.00 & 0.00 & -0.44 & -0.57 & -0.13 & 0.25 & 0.14 & 0.58 \\
\hline$T_{\min } 1800 \mathrm{~m}$ & 0.00 & 0.00 & 0.01 & 0.90 & 0.69 & 0.30 & 0.99 & 0.93 & 0.68 & 0.30 & 0.53 & 0.23 & 0.87 & 0.87 & 1.00 \\
\hline$T_{\max } 1800 \mathrm{~m}$ & 0.00 & 0.00 & 0.00 & 0.84 & 0.74 & 0.08 & 0.98 & 0.95 & 0.31 & 0.20 & 0.38 & 0.18 & 1.00 & 0.91 & 0.91 \\
\hline$T_{\min } 3000 \mathrm{~m}$ & 0.00 & 0.00 & 0.01 & 0.87 & 0.64 & 0.26 & 0.98 & 0.90 & 0.61 & 0.29 & 0.52 & 0.23 & 0.90 & 0.88 & 0.98 \\
\hline$T_{\max } 3000 \mathrm{~m}$ & 0.00 & 0.00 & 0.00 & 0.86 & 0.69 & 0.12 & 0.98 & 0.94 & 0.40 & 0.23 & 0.44 & 0.21 & 0.94 & 0.82 & 0.87 \\
\hline$P_{\text {tot }} 1800 \mathrm{~m}$ & 1.00 & 0.96 & 1.00 & 0.47 & 0.19 & 0.07 & 0.46 & 0.18 & 0.06 & -0.02 & -0.03 & -0.01 & 0.93 & 0.92 & 0.98 \\
\hline SP $1800 \mathrm{~m}$ & 0.00 & 0.00 & 0.00 & 0.22 & 0.03 & 0.01 & 0.03 & 0.00 & 0.00 & -0.17 & -0.35 & -0.18 & 0.64 & 0.44 & 0.69 \\
\hline$P_{\text {tot }} 3000 \mathrm{~m}$ & 1.00 & 0.96 & 1.00 & 0.48 & 0.18 & 0.05 & 0.47 & 0.17 & 0.05 & -0.01 & -0.02 & -0.01 & 0.93 & 0.92 & 0.99 \\
\hline SP $3000 \mathrm{~m}$ & 1.00 & 0.96 & 1.00 & 0.48 & 0.18 & 0.05 & 0.45 & 0.16 & 0.04 & -0.02 & -0.03 & -0.02 & 0.92 & 0.88 & 0.96 \\
\hline HS (1800 m,north) & 0.00 & 0.00 & 0.00 & 0.08 & 0.02 & 0.00 & 0.00 & 0.00 & 0.00 & -0.25 & -0.45 & -0.20 & 0.60 & 0.25 & 0.42 \\
\hline HS (3000 m, north) & 0.03 & 0.00 & 0.01 & 0.19 & 0.07 & 0.00 & 0.04 & 0.01 & 0.00 & -0.20 & -0.37 & -0.17 & 0.75 & 0.63 & 0.84 \\
\hline HS (1800 m, south) & 0.00 & 0.00 & 0.01 & 0.10 & 0.01 & 0.00 & 0.00 & 0.00 & 0.00 & -0.18 & -0.30 & -0.11 & 0.35 & 0.07 & 0.20 \\
\hline HS (3000 m, south) & 0.20 & 0.00 & 0.26 & 0.27 & 0.07 & 0.00 & 0.11 & 0.01 & 0.00 & -0.15 & -0.26 & -0.11 & 0.85 & 0.67 & 0.79 \\
\hline$H_{\mathrm{WS}}(1800 \mathrm{~m}$, north $)$ & 0.01 & 0.00 & 0.84 & 0.66 & 0.54 & 0.19 & 0.76 & 0.66 & 0.16 & 0.27 & 0.33 & 0.06 & 2.39 & 2.81 & 1.17 \\
\hline$H_{\mathrm{WS}}(3000 \mathrm{~m}$, north $)$ & 0.03 & 0.00 & 0.00 & 0.44 & 0.72 & 0.39 & 0.76 & 0.84 & 0.72 & 0.17 & 1.26 & 1.10 & 7.74 & 102.90 & 13.30 \\
\hline$H_{\mathrm{WS}}(1800 \mathrm{~m}$, south $)$ & 0.76 & 0.08 & 0.02 & 0.39 & 0.16 & 0.07 & 0.19 & 0.06 & 0.00 & -0.02 & -0.17 & -0.15 & 1.25 & 0.36 & 0.29 \\
\hline$H_{\mathrm{WS}}(3000 \mathrm{~m}$, south $)$ & 0.11 & 0.00 & 0.15 & 0.54 & 0.30 & 0.13 & 0.68 & 0.37 & 0.10 & 0.13 & 0.20 & 0.07 & 2.01 & 2.35 & 1.17 \\
\hline$H_{\mathrm{DS}}(1800 \mathrm{~m}$, north $)$ & 0.00 & 0.00 & 0.00 & 0.07 & 0.00 & 0.00 & 0.00 & 0.00 & 0.00 & -0.27 & -0.44 & -0.17 & 0.44 & 0.15 & 0.35 \\
\hline$H_{\mathrm{DS}}(3000 \mathrm{~m}$, north $)$ & 0.20 & 0.00 & 0.08 & 0.29 & 0.06 & 0.01 & 0.10 & 0.01 & 0.00 & -0.12 & -0.23 & -0.11 & 0.66 & 0.43 & 0.65 \\
\hline$H_{\mathrm{DS}}(1800 \mathrm{~m}$, south $)$ & 0.00 & 0.00 & 0.00 & 0.08 & 0.00 & 0.00 & 0.00 & 0.00 & 0.00 & -0.24 & -0.38 & -0.15 & 0.38 & 0.14 & 0.38 \\
\hline$H_{\mathrm{DS}}(3000 \mathrm{~m}$, south $)$ & 0.20 & 0.04 & 0.26 & 0.32 & 0.07 & 0.01 & 0.16 & 0.01 & 0.00 & -0.11 & -0.20 & -0.08 & 0.70 & 0.47 & 0.68 \\
\hline$T_{\min } 1800 \mathrm{~m}$ & 0.00 & 0.00 & 0.00 & 0.99 & 0.96 & 0.66 & 1.00 & 1.00 & 0.98 & 0.50 & 0.86 & 0.36 & 0.84 & 0.92 & 1.10 \\
\hline$T_{\max } 1800 \mathrm{~m}$ & 0.00 & 0.00 & 0.00 & 0.97 & 0.83 & 0.60 & 1.00 & 1.00 & 0.98 & 0.45 & 0.92 & 0.47 & 0.86 & 1.04 & 1.21 \\
\hline$T_{\min } 3000 \mathrm{~m}$ & 0.00 & 0.00 & 0.00 & 0.97 & 0.89 & 0.58 & 1.00 & 0.99 & 0.94 & 0.36 & 0.64 & 0.29 & 0.84 & 0.99 & 1.17 \\
\hline$T_{\max } 3000 \mathrm{~m}$ & 0.00 & 0.00 & 0.00 & 0.96 & 0.89 & 0.46 & 1.00 & 1.00 & 0.93 & 0.36 & 0.73 & 0.36 & 0.85 & 1.00 & 1.19 \\
\hline$P_{\text {tot }} 1800 \mathrm{~m}$ & 1.00 & 0.88 & 0.48 & 0.54 & 0.27 & 0.08 & 0.45 & 0.19 & 0.05 & 0.02 & -0.03 & -0.05 & 1.06 & 1.01 & 0.96 \\
\hline SP $1800 \mathrm{~m}$ & 0.00 & 0.00 & 0.01 & 0.06 & 0.00 & 0.00 & 0.00 & 0.00 & 0.00 & -0.31 & -0.47 & -0.17 & 0.51 & 0.26 & 0.52 \\
\hline$P_{\text {tot }} 3000 \mathrm{~m}$ & 0.94 & 0.29 & 0.46 & 0.53 & 0.33 & 0.04 & 0.43 & 0.25 & 0.02 & 0.02 & -0.03 & -0.05 & 1.04 & 0.98 & 0.95 \\
\hline SP $3000 \mathrm{~m}$ & 0.34 & 0.00 & 0.01 & 0.40 & 0.22 & 0.02 & 0.12 & 0.04 & 0.00 & -0.05 & -0.21 & -0.16 & 0.97 & 0.70 & 0.72 \\
\hline HS (1800 m, north) & 0.00 & 0.00 & 0.00 & 0.00 & 0.00 & 0.00 & 0.00 & 0.00 & 0.00 & -0.39 & -0.56 & -0.18 & 0.31 & 0.07 & 0.23 \\
\hline HS (3000 m, north) & 0.01 & 0.00 & 0.03 & 0.18 & 0.04 & 0.00 & 0.03 & 0.00 & 0.00 & -0.25 & -0.54 & -0.28 & 0.96 & 1.00 & 1.04 \\
\hline HS (1800 m, south) & 0.00 & 0.00 & 0.00 & 0.01 & 0.00 & 0.00 & 0.00 & 0.00 & 0.00 & -0.24 & -0.30 & -0.06 & 0.09 & 0.01 & 0.09 \\
\hline HS (3000 m, south) & 0.01 & 0.00 & 0.07 & 0.21 & 0.05 & 0.01 & 0.04 & 0.00 & 0.00 & -0.20 & -0.37 & -0.17 & 0.92 & 0.67 & 0.72 \\
\hline$H_{\mathrm{WS}}(1800 \mathrm{~m}$, north $)$ & 0.00 & 0.00 & 0.00 & 0.03 & 0.00 & 0.00 & 0.00 & 0.00 & 0.00 & -0.34 & -0.57 & -0.23 & 0.43 & 0.11 & 0.25 \\
\hline$H_{\mathrm{WS}}(3000 \mathrm{~m}$, north $)$ & 0.00 & 0.00 & 0.27 & 0.97 & 0.97 & 0.74 & 0.99 & 0.99 & 0.87 & 0.66 & 0.86 & 0.21 & 2.57 & 3.20 & 1.25 \\
\hline$H_{\mathrm{WS}}(1800 \mathrm{~m}$, south $)$ & 0.00 & 0.00 & 0.00 & 0.06 & 0.00 & 0.00 & 0.00 & 0.00 & 0.00 & -0.25 & -0.32 & -0.08 & 0.15 & 0.01 & 0.07 \\
\hline$H_{\mathrm{WS}}(3000 \mathrm{~m}$, south $)$ & 0.00 & 0.09 & 0.17 & 0.81 & 0.65 & 0.22 & 0.71 & 0.54 & 0.17 & 0.26 & 0.18 & -0.08 & 1.50 & 1.76 & 1.17 \\
\hline$H_{\mathrm{DS}}(1800 \mathrm{~m}$, north $)$ & 0.00 & 0.00 & 0.01 & 0.01 & 0.00 & 0.00 & 0.00 & 0.00 & 0.00 & -0.33 & -0.44 & -0.11 & 0.27 & 0.11 & 0.40 \\
\hline$H_{\mathrm{DS}}(3000 \mathrm{~m}$, north $)$ & 0.05 & 0.00 & 0.03 & 0.15 & 0.05 & 0.00 & 0.01 & 0.00 & 0.00 & -0.20 & -0.35 & -0.15 & 0.54 & $\mathbf{0 . 3 3}$ & 0.62 \\
\hline$H_{\mathrm{DS}}(1800 \mathrm{~m}$, south $)$ & 0.00 & 0.00 & 0.04 & 0.01 & 0.00 & 0.00 & 0.00 & 0.00 & 0.00 & -0.34 & -0.46 & -0.12 & 0.27 & 0.10 & 0.37 \\
\hline$H_{\text {DS }}(3000 \mathrm{~m}$, south $)$ & 0.03 & 0.00 & 0.01 & 0.16 & 0.03 & 0.00 & 0.01 & 0.00 & 0.00 & -0.20 & -0.36 & -0.17 & 0.51 & 0.29 & 0.57 \\
\hline
\end{tabular}

$T$ : temperature; $P_{\text {tot }}$ : total precipitation; SP: snow precipitation; HS: snow depth; $H_{\mathrm{WS}}$ : thickness of wet snow; $H_{\mathrm{DS}}$ : thickness of recent surface dry snow. 
Table 6. Changes in CI models between the reference period and the two future periods. "Ref", 2020-2050 and 2070-2100 correspond, respectively, to the three considered periods - the reference period (1960-1990) and the middle and end of the 21st century. Details of the table are the same as for Table 5 .

\begin{tabular}{|c|c|c|c|c|c|c|c|c|c|c|c|c|c|c|c|}
\hline & \multicolumn{3}{|c|}{$\begin{array}{c}\text { Distribution comparison } \\
\text { ( } p \text { value, Kolmogorov-Smirnov test) }\end{array}$} & \multicolumn{3}{|c|}{$\begin{array}{l}\text { Prob. mean } \\
(2020-2050)>\end{array}$} & \multicolumn{3}{|c|}{$\begin{array}{l}\text { Prob. mean } \\
(2070-2100)>\end{array}$} & \multicolumn{3}{|c|}{$\begin{array}{c}\text { Means comparison } \\
\text { (standardized differences) }\end{array}$} & \multicolumn{3}{|c|}{$\begin{array}{l}\text { Variance comparison } \\
\text { (ratios) }\end{array}$} \\
\hline & $\begin{array}{r}\text { Ref/ } \\
2020-2050\end{array}$ & $\begin{array}{r}\text { Ref/ } \\
2070-2100\end{array}$ & $\begin{array}{r}2020-2050 / \\
2070-2100\end{array}$ & $\begin{array}{r}\text { Mean } \\
(\text { ref) }\end{array}$ & $\begin{array}{r}\mathrm{q} 75 \\
\text { (ref) }\end{array}$ & $\begin{array}{r}\text { q95 } \\
\text { (ref) }\end{array}$ & $\begin{array}{r}\text { Mean } \\
\text { (ref) }\end{array}$ & $\begin{array}{r}\mathrm{q} 75 \\
\text { (ref) }\end{array}$ & $\begin{array}{r}\mathrm{q} 95 \\
\text { (ref) }\end{array}$ & $\begin{array}{r}2020 / 2050 \\
- \text { ref }\end{array}$ & $\begin{array}{r}2070 / 2100 \\
- \text { ref }\end{array}$ & $\begin{array}{r}2070 / 2100 \\
-2020 / 2050\end{array}$ & $\begin{array}{r}2020 / 2050 \\
- \text { ref }\end{array}$ & $\begin{array}{r}2070 / 2100 \\
- \text { ref }\end{array}$ & $\begin{array}{r}2070 / 2100 \\
-2020 / 2050\end{array}$ \\
\hline French Alps, year & 0.00 & 0.00 & 0.00 & 0.00 & 0.00 & 0.00 & 0.04 & 0.00 & 0.00 & -0.19 & -0.26 & -0.06 & 0.06 & 0.03 & 0.44 \\
\hline French Alps, winter & 0.01 & 0.00 & 0.01 & 0.72 & 0.61 & 0.44 & 0.87 & 0.80 & 0.70 & 0.30 & 1.27 & 0.97 & 4.34 & 37.43 & 8.62 \\
\hline French Alps, spring & 0.00 & 0.00 & 0.01 & 0.01 & 0.00 & 0.00 & 0.00 & 0.00 & 0.00 & -0.43 & -0.56 & -0.13 & 0.41 & 0.20 & 0.48 \\
\hline North. French Alps, year & 0.00 & 0.00 & 0.07 & 0.00 & 0.00 & 0.00 & 0.00 & 0.00 & 0.00 & -0.44 & -0.54 & -0.10 & 0.31 & 0.24 & 0.78 \\
\hline North. French Alps, winter & 0.20 & 0.00 & 0.22 & 0.32 & 0.10 & 0.00 & 0.12 & 0.01 & 0.00 & -0.10 & -0.21 & -0. & 0.62 & 0.39 & 0.63 \\
\hline North. French Alps, spring & 0.00 & 0.00 & 0.00 & 0.01 & 0.00 & 0.00 & 0.00 & 0.00 & 0.00 & -0.42 & -0.63 & -0.22 & 0.45 & 0.22 & 0.49 \\
\hline South. French Alps, year & 0.00 & 0.00 & 0.36 & 0.02 & 0.00 & 0.00 & 0.00 & 0.00 & 0.00 & -0.30 & -0.33 & -0.03 & 0.11 & 0.03 & 0.29 \\
\hline South. French Alps, winter & 0.05 & 0.00 & 0.03 & 0.62 & 0.50 & 0.29 & 0.87 & 0.80 & 0.56 & 0.31 & 0.95 & 0.64 & 7.05 & 24.32 & 3.45 \\
\hline South. French Alps, spring & 0.00 & 0.00 & 0.00 & 0.05 & 0.02 & 0.00 & 0.01 & 0.00 & 0.00 & -0.29 & -0.36 & -0.07 & 0.19 & 0.09 & 0.46 \\
\hline
\end{tabular}

Table 7. Changes in MEPRA index between the reference period and the two future periods. "Ref", 2020-2050 and 2070-2100 correspond, respectively, to the three considered periods - the reference period (1960-1990) and the middle and end of the 21st century, respectively. Details of the table are the same as for Table 5.

\begin{tabular}{|c|c|c|c|c|c|c|c|c|c|c|c|c|c|c|c|}
\hline & \multicolumn{3}{|c|}{$\begin{array}{c}\text { Distribution comparison } \\
\text { ( } p \text { value, Kolmogorov-Smirnov test) }\end{array}$} & \multicolumn{3}{|c|}{$\begin{array}{l}\text { Prob. mean } \\
(2020-2050)>\end{array}$} & \multicolumn{3}{|c|}{$\begin{array}{l}\text { Prob. mean } \\
(2070-2100)>\end{array}$} & \multicolumn{3}{|c|}{$\begin{array}{c}\text { Means comparison } \\
\text { (standardized differences) }\end{array}$} & \multicolumn{3}{|c|}{$\begin{array}{l}\text { Variance comparison } \\
\text { (ratios) }\end{array}$} \\
\hline & $\begin{array}{r}\text { Ref/ } \\
2020-2050\end{array}$ & $\begin{array}{r}\text { Ref/ } \\
2070-2100\end{array}$ & $\begin{array}{r}2020-2050 / \\
2070-2100\end{array}$ & $\begin{array}{r}\text { Mean } \\
\text { (ref) }\end{array}$ & $\begin{array}{r}\mathrm{q} 75 \\
\text { (ref) }\end{array}$ & $\begin{array}{r}\mathrm{q} 95 \\
\text { (ref) }\end{array}$ & $\begin{array}{r}\text { Mean } \\
(\mathrm{ref})\end{array}$ & $\begin{array}{r}\mathrm{q} 75 \\
\text { (ref) } \\
\end{array}$ & $\begin{array}{r}\text { q95 } \\
\text { (ref) }\end{array}$ & $\begin{array}{r}2020 / 2050 \\
- \text { ref }\end{array}$ & $\begin{array}{r}2070 / 2100 \\
- \text { ref }\end{array}$ & $\begin{array}{r}2070 / 2100 \\
-2020 / 2050 \\
\end{array}$ & $\begin{array}{r}2020 / 2050 \\
- \text { ref }\end{array}$ & $\begin{array}{r}2070 / 2100 \\
- \text { ref }\end{array}$ & $\begin{array}{r}2070 / 2100 \\
-2020 / 2050 \\
\end{array}$ \\
\hline French Alps, year & 0.34 & 0.00 & 0.00 & 0.37 & 0.17 & 0.01 & 0.05 & 0.01 & 0.00 & -0.08 & -0.31 & -0.23 & 0.93 & 0.53 & 0.58 \\
\hline French Alps, winter & 0.20 & 0.00 & 0.17 & 0.33 & 0.16 & 0.00 & 0.13 & 0.03 & 0.00 & -0.08 & -0.18 & -0.09 & 0.77 & 0.49 & 0.65 \\
\hline French Alps, spring & 0.34 & 0.01 & 0.00 & 0.59 & 0.34 & 0.08 & 0.20 & 0.05 & 0.00 & 0.08 & -0.23 & -0.31 & 1.21 & 0.75 & 0.62 \\
\hline North. French Alps, year & 0.54 & 0.00 & 0.00 & 0.44 & 0.26 & 0.02 & 0.09 & 0.02 & 0.00 & -0.04 & -0.26 & -0.22 & 1.01 & 0.59 & 0.58 \\
\hline North. French Alps, winter & 0.54 & 0.02 & 0.18 & 0.39 & 0.20 & 0.00 & 0.16 & 0.05 & 0.00 & -0.06 & -0.16 & -0.10 & 0.83 & 0.52 & 0.62 \\
\hline North. French Alps, spring & 0.20 & 0.13 & 0.03 & 0.65 & 0.39 & 0.14 & 0.29 & 0.08 & 0.01 & 0.12 & -0.14 & -0.26 & 1.39 & 0.91 & 0.66 \\
\hline South. French Alps, year & 0.00 & 0.00 & 0.00 & 0.32 & 0.20 & 0.08 & 0.19 & 0.10 & 0.03 & -0.16 & -0.31 & -0.15 & 0.87 & 0.55 & 0.63 \\
\hline South. French Alps, winter & 0.03 & 0.00 & 0.37 & 0.27 & 0.15 & 0.02 & 0.21 & 0.10 & 0.01 & -0.17 & -0.23 & -0.06 & 0.65 & 0.49 & 0.76 \\
\hline South. French Alps, spring & 0.54 & 0.00 & 0.00 & 0.38 & 0.24 & 0.08 & 0.18 & 0.10 & 0.01 & -0.05 & -0.25 & -0.20 & 1.17 & 0.68 & 0.58 \\
\hline
\end{tabular}

computed from the normal fit on the $X_{t}$ samples when possible (i.e. when the Gaussian assumption could not be rejected) and from the Kernel smoothing approximation of the empirical cumulative distribution function (cdf), introduced previously, otherwise.

Finally, we also tested the difference between the multivariate distributions of annual/seasonal variables corresponding to each of the CI models (that is, for each of the nine regression models, the joint distribution of the variables $X_{j t}^{\text {norm }}$, $j=[1, P]$ number of covariates), using the Cramer test (Table 8$)$.

\section{Results}

\subsection{Meteorological and snowpack conditions in the future}

Meteorological and snowpack conditions in the future on the massif and annual scales are presented and discussed in detail by Rousselot et al. (2012). Here, we complement the analysis by assessing changes between reference and future periods in terms of probabilities of exceeding distribution percentiles during the reference period in the future and by assessing normalized differences and ratios for the nine spatio-temporal scales we consider. We also expand this approach to snowpack variables that are more directly relevant for avalanche activity and that were not considered in the previous study (e.g. snow conditions on slopes and recent surface dry/wet snow thickness). Figures 4-8 illustrate regional north-south differences with regard to the whole French Alps, while Table 5 shows detailed results for the entire French Alps only but only displays results for the three considered time periods, highlighting seasonal variations. In what follows we focus on projections concerning the A1B scenario (IPCC, 2007) only.

In Table 5, it is important to note that differences in probabilities of exceeding percentiles can be insignificant if underlying distributions are not different (null hypothesis not rejected by the Kolmogorov-Smirnov test). Hence, significant differences are shown in bold; for the whole year, it is generally the case for all variables between reference and 2020-2050 periods, except for the total precipitation and for the thickness of wet snow at $3000 \mathrm{~m}$ for a south-facing slope. Similarly, normalized differences in interannual means and variance ratios are often high and far from 1, respectively, but testing the significance of these changes could not always be done, depending on the Shapiro-Wilk and Fisher test results. Significant differences are shown in bold whereas values whose significance could not be tested are shown in grey.

\subsubsection{Temperatures}

As expected, between the reference period and the mid 21st century, temperatures were found to increase significantly. 
Table 8. Changes in snow and climate multivariate distributions corresponding to each CI model and $p$ values of the Cramer test. Bold values are lower than 0.05 , indicating significant differences at the $95 \%$ level.

\begin{tabular}{lrrr}
\hline & $\begin{array}{r}\text { Reference } \\
\text { vs. 2020-2050 }\end{array}$ & $\begin{array}{r}\text { Reference } \\
\text { vs. 2070-2100 }\end{array}$ & $\begin{array}{r}2020-2050 \\
\text { vs. 2070-2100 }\end{array}$ \\
\hline French Alps, year & $<\mathbf{1 0}^{-3}$ & $<\mathbf{1 0}^{-3}$ & $<\mathbf{1 0}^{-3}$ \\
French Alps, winter & $\mathbf{0 . 0 3}$ & $<\mathbf{1 0}^{-3}$ & $\mathbf{0 . 0 2}^{-3}$ \\
French Alps, spring & $<\mathbf{1 0}^{-3}$ & $<\mathbf{1 0}^{-3}$ & $\mathbf{0 . 0 0 2}$ \\
North. French Alps, year & $<\mathbf{1 0}^{-3}$ & $<\mathbf{1 0}^{-3}$ & $<\mathbf{1 0}^{-3}$ \\
North. French Alps, winter & 0.13 & $<\mathbf{1 0}^{-3}$ & 0.08 \\
North. French Alps, spring & $\mathbf{0 . 0 3}^{-3}$ & $<\mathbf{1 0}^{-3}$ & $\mathbf{0 . 0 0 3}^{-3}$ \\
South. French Alps, year & $<\mathbf{1 0}^{-3}$ & $<\mathbf{1 0}^{-3}$ & $<\mathbf{1 0}^{-3}$ \\
South. French Alps, winter & 0.1 & $\mathbf{0 . 0 2}^{-3}$ & 0.09 \\
South. French Alps, spring & $<\mathbf{1 0}^{-3}$ & $<\mathbf{1 0}^{-3}$ & $<\mathbf{1 0}^{-3}$ \\
\hline
\end{tabular}

This increase continues towards the late 21 st century (20702100). The increase is very homogeneous over the Alps and concerns daily, minimal and maximal values as well as low $(1800 \mathrm{~m})$, medium $(2400 \mathrm{~m})$ and high elevations $(3000 \mathrm{~m}$, Fig. 4). For example, on the annual scale and for the entire French Alps, standardized anomalies indicate a mean increase of about $60 / 75 \%$ in the mid 21 st century as compared to the reference period. Hence, the mean over the reference period is already exceeded almost certainly for all the years simulated under this changed climate. Even more impressively, the $75 \%$ percentile of the reference sample is exceeded for nearly all the years simulated for the late $21 \mathrm{st}$ century with $a \sim+115 / 155 \%$ mean increase in standardized anomaly compared to the reference period. On the other hand, an increase during the winter season is expected to be a bit less great than during the spring season, e.g. $+40-55 \%$ vs. $+65-90 \%$ mean increase towards the late 21 st century in winter/spring, respectively, for the entire French Alps (Table 5). For all periods/seasons, variance ratios are within the 0.8-1.2 range, indicating moderate and often insignificant changes not higher than $20 \%$ in interannual variability, even between the reference period and the late 21st century (Table 5).

\subsubsection{Total and snow precipitation}

The projections of climate change used only slightly impacts total precipitation on any considered spatio-temporal scales only slightly, with very small changes in distribution/mean/interannual variability as compared to the reference period, even towards the late 21st century (Fig. 5 and Table 5). It can only be noted that differences in mean standardized anomalies are always negative, with a maximal amplitude of around $-15 \%$ for the southern French Alps towards the late 21 st century. This negative sign may be seen as surprising when compared to the results obtained by many authors with various GCM-RCM projections, often showing slightly increasing precipitation in the future. In our opinion, rather than a specificity of our RCM, a possible explana- tion of our negative sign may be the way we compute differences with regard to the reference period; our method differs slightly compared to the one generally considered in the literature. Also, the specificity of the 1960-1990 reference period in the mountain region we consider (rather cold; see Sect. 4 for discussion) may be an issue, so that other reference period choices may lead to slightly different results in terms of relative changes. However, the main thing about our precipitation results is that the changes we highlight are almost always statistically insignificant, so that the null hypothesis of no change should instead be considered in potential practical outlooks of our study.

In contrast, the phase of precipitation is strongly impacted by warming, leading to rather strong decreases in snow precipitation. This is especially true at low elevations, during spring as compared to the winter period (Table 5),= and, at a lesser extent, for the southern French Alps as compared to the northern ones (Fig. 5). The reason is that, for a given altitude, the solar radiation is stronger in spring and/or for the southern region. As expected, the decrease goes on with warming from the mid to the late 21 st century. It is noteworthy that the reduction in mean is also accompanied by a rather strong decrease in interannual variability, because annual snowfall much higher than the interannual mean becomes more and more seldom. For example, for the entire French Alps, on an annual scale, at $1800 \mathrm{~m}$, the decrease in mean standardized anomaly is around -30 and $-50 \%$ towards the mid and late 21 st century, respectively, with a variance ratio between the late 21 st century and the reference period of only 0.4 . These changes lead to the fact that, for the late 21 st century one no longer expects any year with a total snowfall as high as the mean during the reference period (Table 5). Note, however, that changes are much smaller at high altitudes because temperature increase is then not sufficient to significantly impact the precipitation phase (Fig. 5 and Table 5). 
a) Tmin, $1800 \mathrm{~m}$

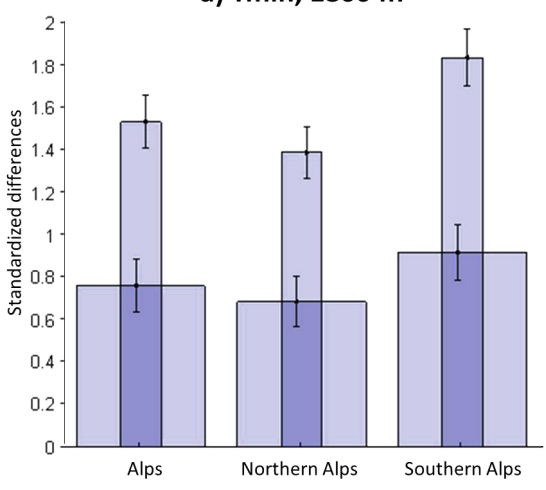

c) Tmin, $\mathbf{3 0 0 0 ~ m ~}$

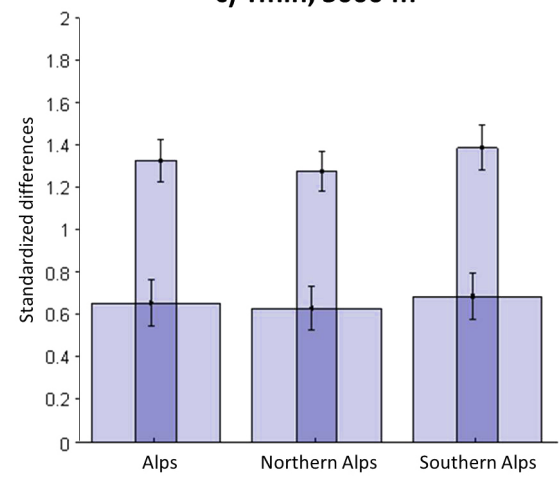

b) Tmax, $1800 \mathrm{~m}$

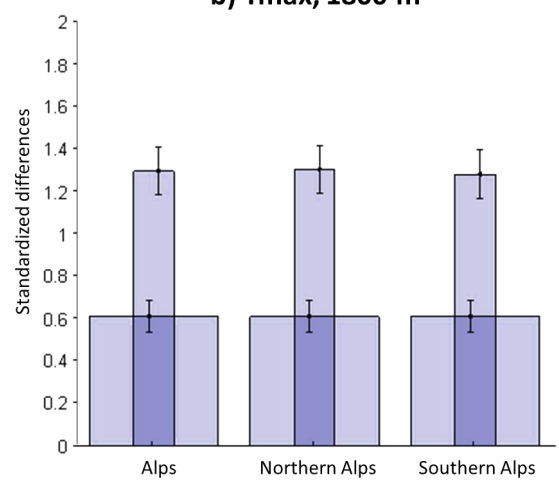

d) Tmax, $3000 \mathrm{~m}$

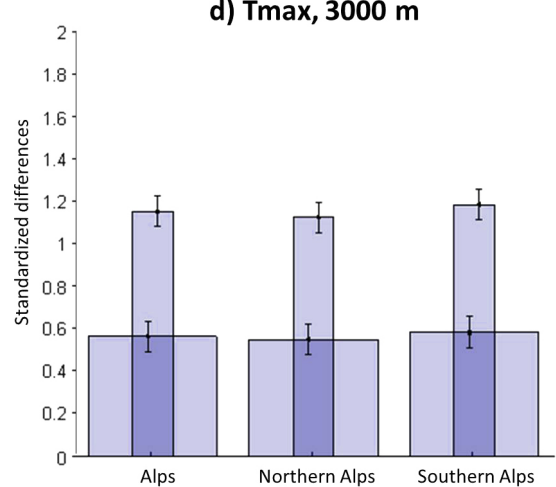

Figure 4. Standardized differences (differences between reference and future-period means divided by the variability range for the reference period) in temperatures (minimal/maximal, at 1800 and $3000 \mathrm{~m}$ a.s.l.) on the scale of the entire French Alps and for the whole year for the middle and end of the 21 st century (wide and thin bars, respectively) for the A1B scenario. Error bars $( \pm 1.5 \sigma)$ represent interannual variability.

\subsubsection{Snow depth}

Concerning snowpack characteristics following snow precipitation changes, snow depths in future strongly decrease in terms of distribution, interannual mean and interannual variability (Fig. 6). Expected changes are stronger between the reference period and the mid 21 st century than between mid and late 21 st century: $-15-60 \%$ and $-25-85 \%$ towards the mid and late 21 st century in terms of standardized mean, respectively, for the entire French Alps over the different altitudes, slopes and timescales. Corresponding variance ratios also decrease, leading to small (if not 0 ) probabilities of exceeding the reference mean already in 2020-2050 (Table 5). With regard to snow precipitations, changes in interannual means are more homogeneous between regions and even elevations. This arises because, even if snow precipitation is better conserved at $3000 \mathrm{~m}$ under a future climate, warmer temperatures lead to accelerated melting during spring and to a higher snowpack bulk density at all altitudes, resulting in smaller corresponding snow depths. It can, however, be noted that the decrease is slightly more marked for northfacing slopes than for south ones, presumably because mod- ified meteorological conditions induce more snowmelt in the future than currently on these slopes. In addition, the reduction of the interannual variability affects south-facing slopes much more than north ones, especially at low altitudes, because, for south-facing slopes, the annual mean snow depth is very small for each year of the future simulation, leading to much lower variance, for example, only $1-25 \%$ of that of the reference period in the late 21st century for the entire French Alps over the full year (Table 5).

\subsubsection{Wet- and dry-snow depths}

Thicknesses of wet snow (Fig. 7) at $1800 \mathrm{~m}$ are characterized by negative differences in interannual means and small variance ratios as compared to the reference period, means characteristics which increase at the end of the 21 st century. This is directly linked with the small (often close to 0 according to exceedance probabilities) snow depth values expected in future at this elevation (Table 5). In contrast, at high elevation, especially for northern slopes, wetsnow amounts are expected to greatly increase compared to the reference period where they used to be negligible due 

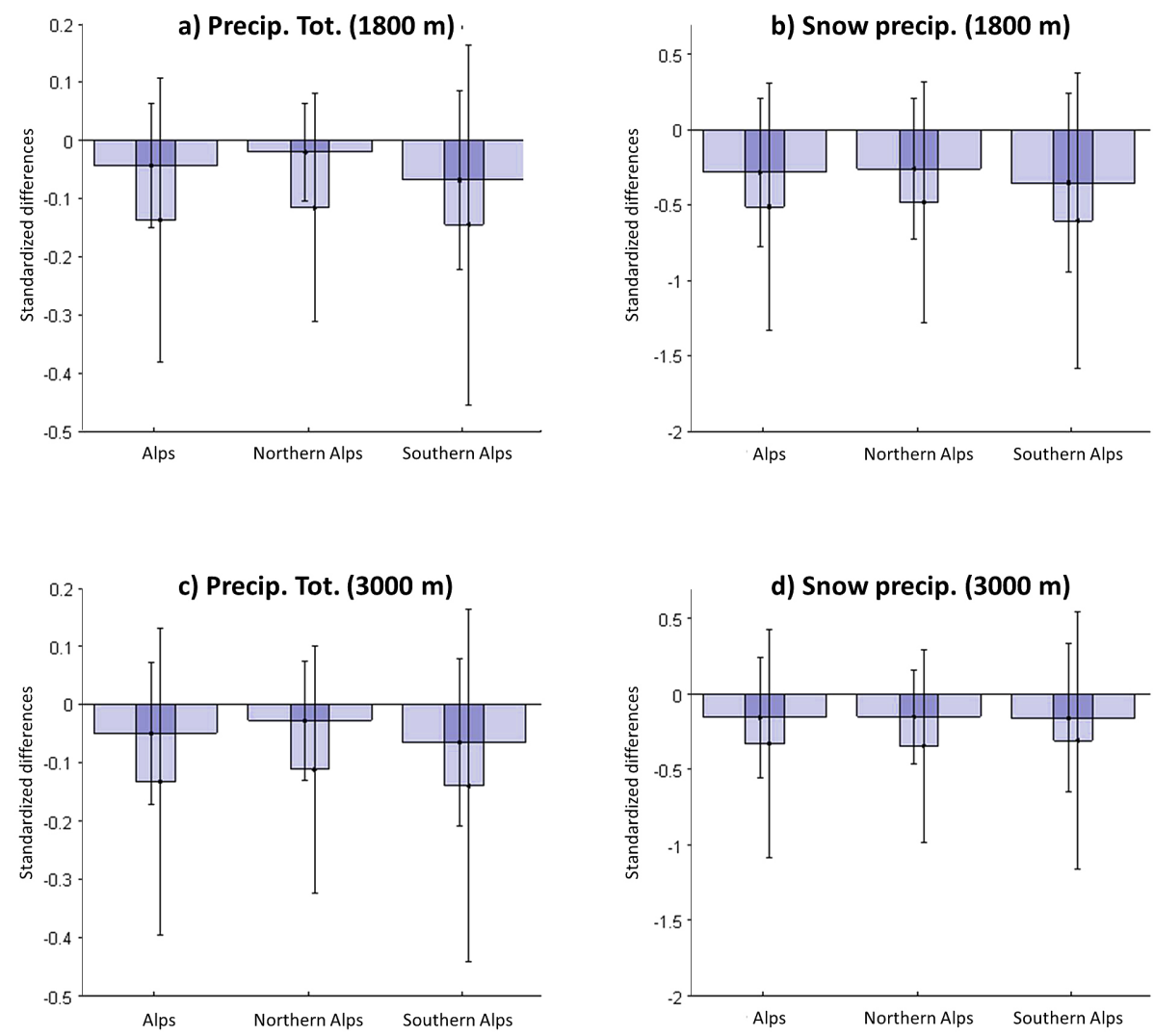

Figure 5. Same as for Fig. 4 but with regard to precipitation (total/snow at 1800 and $3000 \mathrm{~m}$ a.s.1.).

to predominantly non-melting conditions (sufficiently cold temperatures). Similarly to snow depth, predicted differences are often less important between the mid and late 21 st century than between the reference period and the mid 21 st century. They can even be less important between the reference period and the end of the 21 st century than between the reference period and the mid 21 st century when the warming becomes important enough to preclude very high snow depths even at high elevation. For example, for the entire French Alps on the annual timescale, for a north-facing slope at $3000 \mathrm{~m}$, the interannual mean increase compared to the reference period is $+104 \%$ and $+76 \%$ towards the mid and late 21st century, respectively (Table 5).

Regional north-south differences are quite small. It can only be noted that the high altitude increase is slightly more marked in the northern French Alps (Fig. 7). In terms of seasonal differences, in addition to the high-altitude increase/low-altitude decrease visible on the annual scale and generally enhanced for the spring season, one can note a moderate low-altitude increase in wet-snow depth during winter for north-facing slopes $(+27 \%$ and $+33 \%$ towards the mid and late 21 st century, respectively; Table 5) that used to be small during the reference period.

On the other hand, following temperature and precipitation phase changes, thicknesses of recent dry snow are pro- jected to decrease in the future, noteworthy already for the mid 21 st century when compared to the reference period. On the annual timescale, the $-40-50 \%$ and $-50-70 \%$ decrease in interannual mean for the mid and late 21 st century, respectively, accompanied by a strong reduction of interannual variability, is rather homogeneous for the different slopes, elevations or regions (Fig. 8). This leads to the probability of exceeding reference values in a future climate becoming even smaller than for snow depth values (Table 5). As for many other variables, the decrease appears slightly more marked during the spring season, with e.g. $-10-25 \%$ and $-20-35 \%$ for the entire French Alps in winter/spring, respectively, for the mid 21 st century compared to the reference period (Table 5).

\subsection{Avalanche activity in the future}

\subsubsection{Projections of CI values}

The Cramer test indicates that the joint distribution of the variables corresponding to each of the fitted regression models is always significantly different in the two future periods (still under the A1B scenario) from the reference period ( $p$ values largely under the 0.05 significance level, Table 8), except for the northern French Alps in winter. For the latter case, the explanation is that the model has one single 

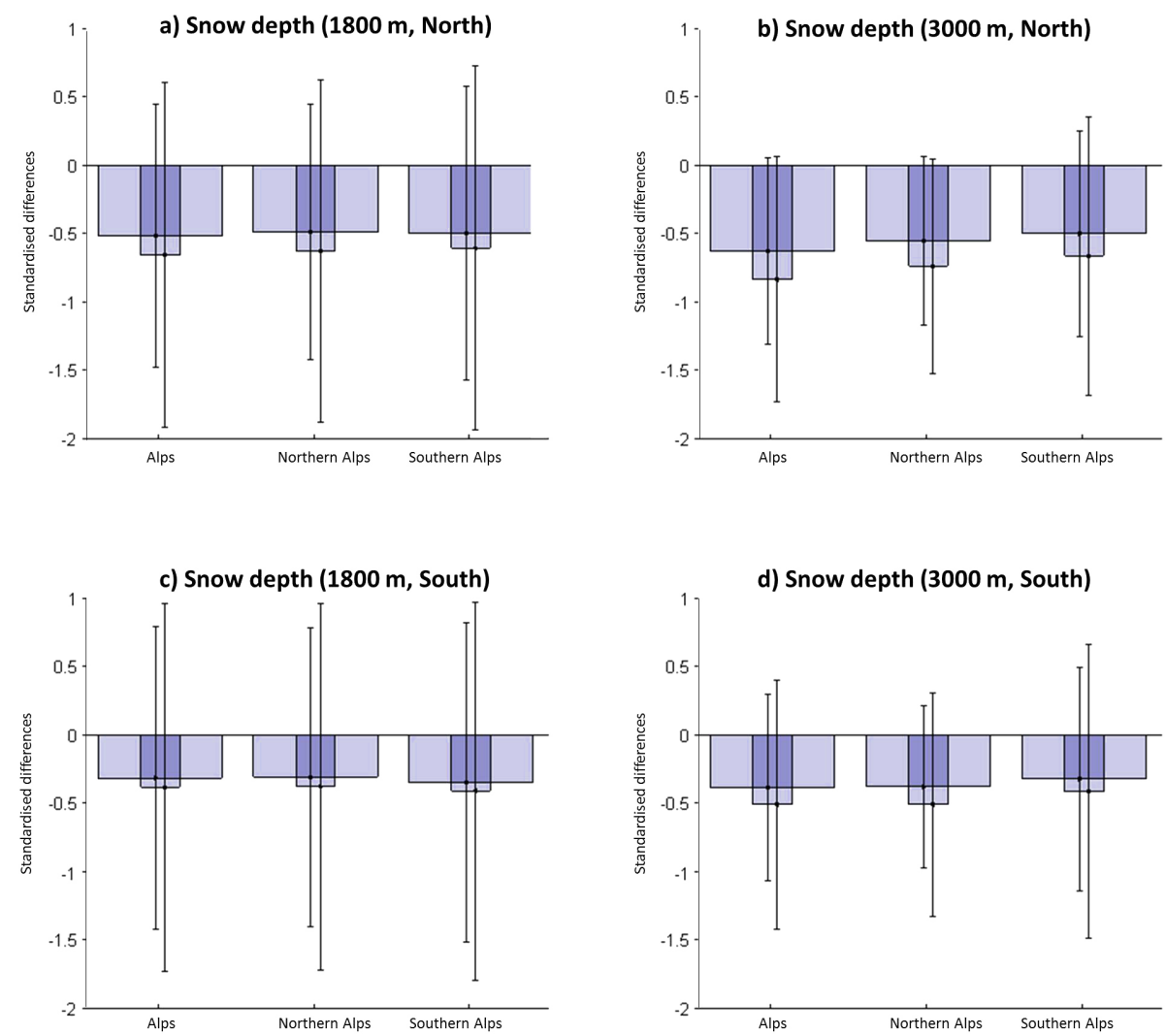

Figure 6. Same as for Fig. 4 but with regard to snow depth (north and south facing slope, at 1800 and $3000 \mathrm{~m}$ a.s.1.).

covariate (Table 2). Significant differences between the two future periods also exist for most of the joint distributions. These results suggest that avalanche activity, as a combination of different nonstationary drivers, may, in the future, encounter changes that are even more important than those expected for each of the snow and meteorological variables.

In more detail, on the scale of the entire French Alps, obtained CI projections (Fig. 3, Sect. 2) show clear decreases for the full year $(-20$ and $-25 \%$ in standardized interannual mean for the mid and late 21 st century, respectively), enhanced for the spring season $(-45$ and $-55 \%$ for the mid and late 21 st century, respectively). These decreases in interannual means are accompanied by strong decreases in interannual variability (Table 6 ). Opposite trends are clear during the winter season: marked increases $(+30$ and $+125 \%$ in standardized interannual mean for the mid and late 21 st century, respectively), strongly driven by dramatic increases in the interannual variability. These results are well illustrated by exceedance probabilities: on the annual scale and during spring, the probability of a future winter showing avalanche activity as high as the reference mean is close to 0 already for mid 21 st century. In contrast, little years with a winter avalanche activity much higher than during the reference period are expected in the future. Indeed, the probabilities for the avalanche activity index in winter to exceed the 95 per- centile of the reference period are as high as 0.44 and 0.7 for the mid and late 21 st century, respectively (Table 6).

These results are direct consequences of the combined evolution of snow and meteorological variables. Whereas precipitation values remain fairly stable, temperature increases interacting with topography control the amount of snow precipitation and snowpack characteristics all over the avalanche year. Overall, the snow precipitation and depth decrease in mean and variance (Figs. 5 and 6), reducing avalanche activity, especially in spring during which changes in snow variables and even in temperatures are particularly strong. On the other hand, more important amounts of wet snow appear earlier in the season, eventually increasing avalanche activity at that time compared to the reference period, at least for certain years (strong increase of the interannual variability in winter). As for the snow and meteorological variables, it is noticeable that most of the forecasted changes are already important for the mid 21 st century. They go on until the end of the 21 st century, but apparently at a slightly slower pace.

Figure 9 shows the CI reference distributions and projections for both sub-regions and the different temporal scales considered. It suggests that the overall decrease in avalanche activity forecasted in terms of the CI for the mid 21st century is mostly driven by a strong decrease in the northern French 

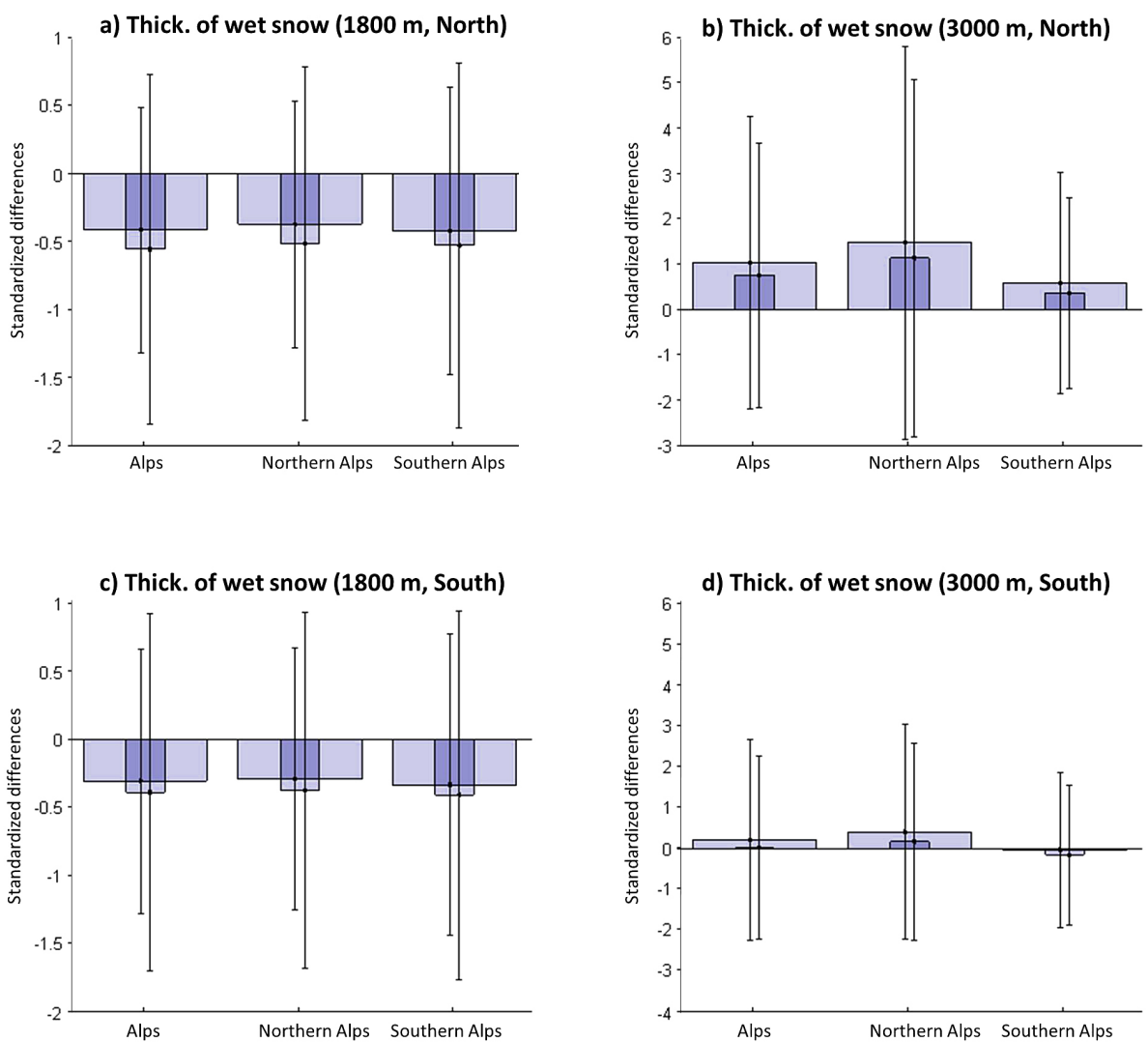

Figure 7. Same as for Fig. 4 but with regard to thickness of wet snow (north and south facing slope, at 1800 and $3000 \mathrm{~m}$ a.s.1.).

Alps during spring, where the decrease is the strongest $(-63 \%$, Table 6$)$, whereas a slight decrease is also predicted in the winter season $(-21 \%)$, contrary to what is expected on the scale of the entire French Alps. By contrast, for the southern Alps, the spring distribution is thinner than for the reference period but with a decrease less marked than on the scale of the entire Alps (-29\%). More dramatically, the winter increase in mean and variance is rather spectacular.

Since the snow and meteorological variable analysis has shown that, at constant altitude, latitudinal gradients (northsouth location within the Alps) have little effect on projected changes, these distinct north-south pictures may be attributable to altitudinal effects. Indeed, several massifs in the northern sub-region ("pre-Alps") have a lower altitudinal distribution, with their highest summits in the $2000-2300 \mathrm{~m}$ altitude range only (Fig. 1). In these pre-Alps massifs, avalanche activity is strongly reduced under climate warming by less abundant snow precipitation and the subsequent snowpack decrease; this applies to the full year and even to winter. This induces a weaker but apparently still significant reduction for the whole northern French Alps. By contrast, in the southern massifs of higher homogeneity in terms of elevation, wetting induced by warmer conditions of the still important high-altitude snowpack in winter leads to more wet snow (Fig. 7) and, therefore, more wet-snow avalanches in addition to the dry-snow releases always possible (at high altitude, dry-snow depths remain significant; Fig. 8). Hence, the refined altitudinal control with distinct effects at different altitudes on north-south-facing slopes that has been highlighted for snowpack variables clearly impacts avalanche activity projections. Note, however, that we cannot refine results as much as for the snow variables, by e.g. analysing north-south behaviours at fixed altitudes and expositions, because avalanche activity indexes are computed as integrated quantities first over massifs and then over regions.

Between the 2020-2050 and 2070-2100 periods, the decreasing trends remain the same for the Northern Alps, again more markedly in spring. On the other hand, the overall annual activity is found to stabilize for the southern Alps ( $-3 \%$ in interannual mean change between the two periods), whereas the winter increase compared to the reference period is becoming less important. This is probably because, at the end of the 21 st century, as shown before, the warming is becoming marked enough to significantly reduce the snowpack (and for instance the dry snowpack), even at high altitude in winter. 

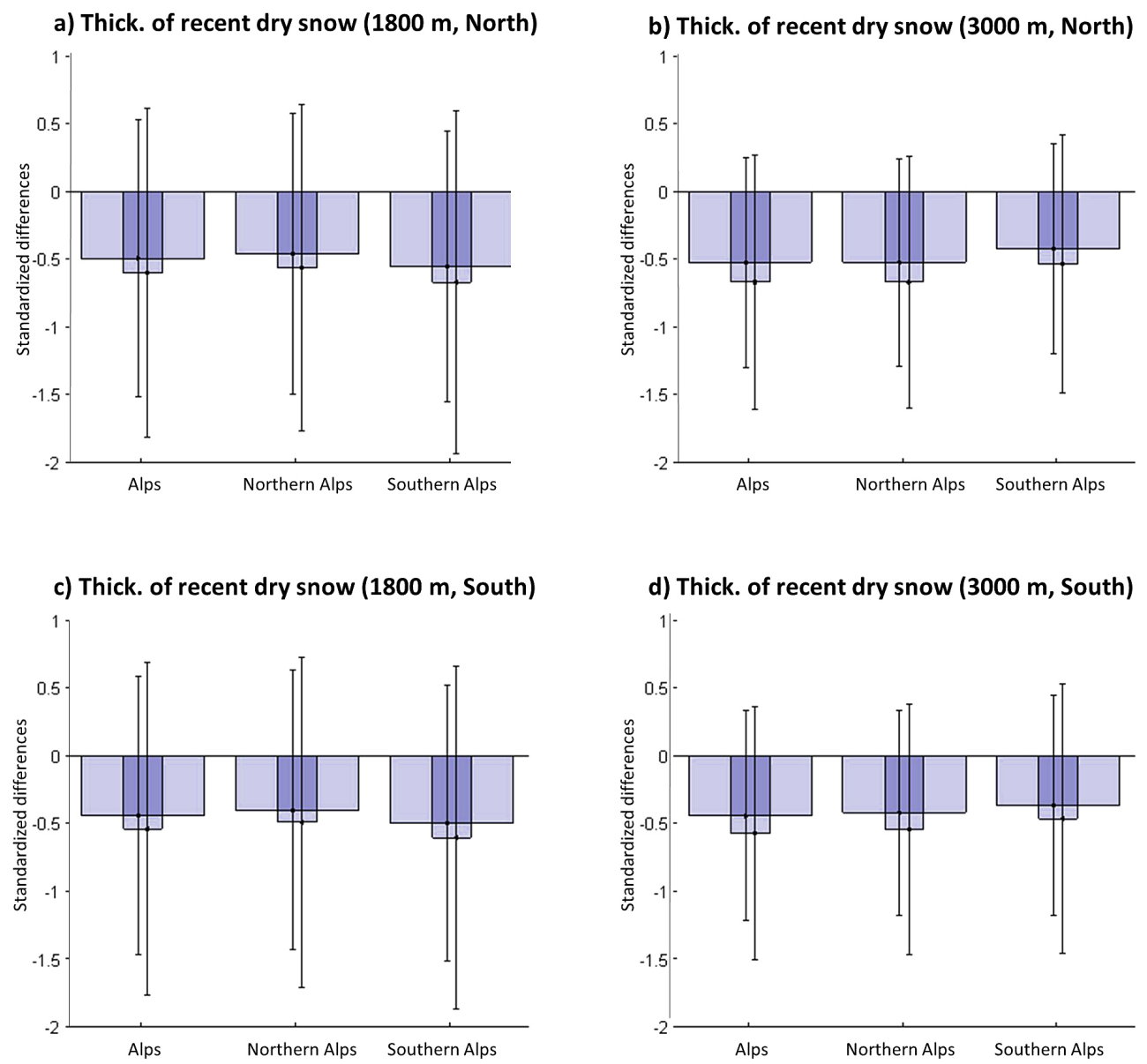

Figure 8. Same as for Fig. 4 but with regard to thickness of recent surface dry snow (north and south facing slope, at 1800 and $3000 \mathrm{~m}$ a.s.1.).

\subsubsection{Comparison of the projected composite index and MEPRA index}

The CI projections are worth comparing with future annual/seasonal means of the computed MI (Table 7 and Figs. 10 and 11). On the scale of the entire Alps and the full year, trends are similar: both indexes decrease for future periods, meaning a decrease in the overall avalanche activity. However, this decrease is more important for the $\mathrm{CI}$ between the reference period and the mid 21st century, whereas the MI decreases notably only between the mid and the late 21 st century $(-8$ and $-31 \%$ in standardized interannual mean compared to the reference period for the mid and late 21 st century, respectively). Furthermore, the relatively high interannual variability still characterizing the MI in a future climate leads to the fact that the probability of exceeding the mean of the reference period remain more significant than those predicted by the CI (Table 7), even if it decreases. Hence, the MI seems to be able to detect "intense" avalanche years (i.e. years with cumulated activity far above the mean) for future periods, whereas the CI forecasts a smoother decreasing trend.
For the winter season (Fig. 10), as discussed before, the CI significantly increases in the future, but with a strong interannual variability. On one hand, the MI indicates little changes, probably due to offset effects between an increase of wetsnow avalanches due to wetter snowpack and, on the other hand, (i) less snow precipitation, leading to a thinner snowpack and fewer dry-snow avalanches and (ii) higher temperatures leading to a more intense snow metamorphism earlier in the season, which results in a reduced level of instability. During spring, as for the annual scale, while the CI strongly decreases for both future periods in mean and variance, the MI only decreases significantly in mean at the end of the 21st century whereas, for the mid 21 st century, projections show a higher interannual variability.

Regarding sub-regions, the main difference to the $\mathrm{CI}$ is that the MI decreases more strongly for the southern French Alps on annual and spring timescales and also decreases in winter while the projected CI values show an increase in avalanche activity. This may indicate that the MI is more sensitive to the expected higher temperatures and the subsequent strong decrease of snow precipitation (Figs. 3 and 4), whereas the stepwise selection procedure has, in this southern region, 
a) Northern Alps, full year

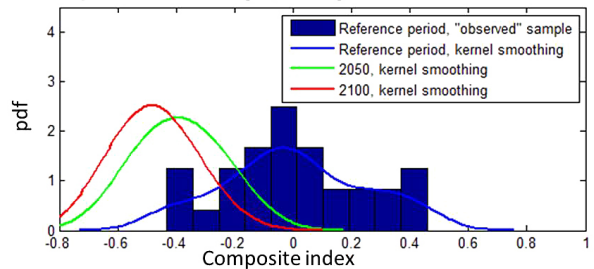

b) Northern Alps, winter

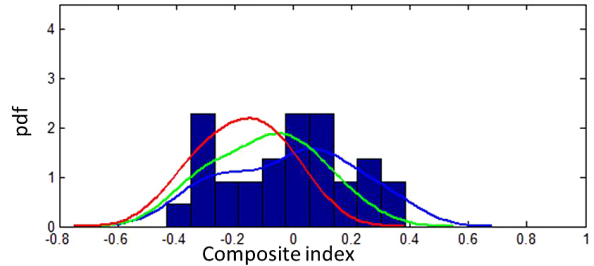

c) Northern Alps, spring

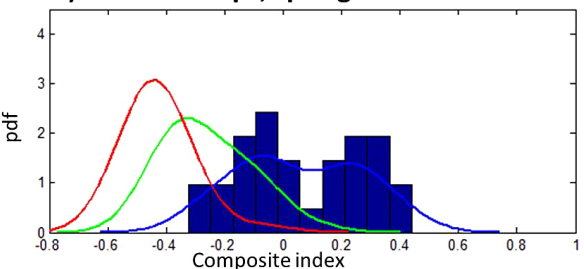

d) Southern Alps, full year

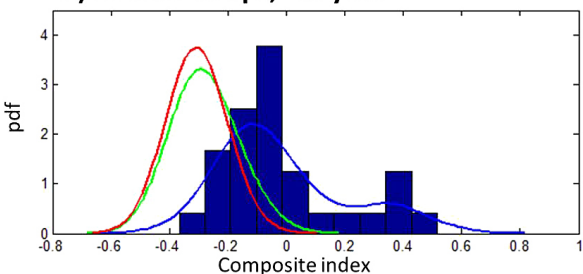

e) Southern Alps, winter

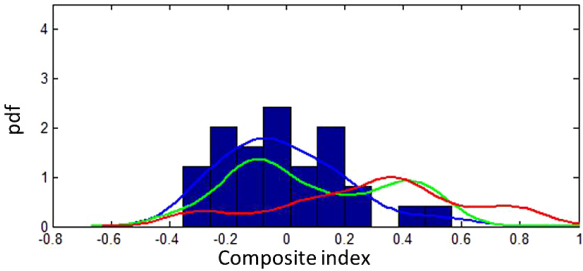

f) Southern Alps, spring

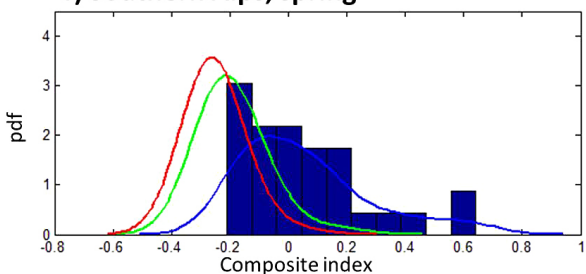

Figure 9. Probability density functions of the composite index during the reference period and the future periods 2020-2050 and 20702100. Northern (left panel) and southern (right panel) French Alps during the full avalanche year (a-d), and the winter (b-e) and spring (c-f) sub-periods.

picked up only CI snowpack variables (Table 3) which are less affected due to the high altitude of the massifs or are even destabilized earlier in season by warming as discussed Sect. 3.2.1. By contrast, for the northern French Alps, the decrease forecasted by the MI is less strong than predicted by the CI, especially for the mid century.

Scatter plots for the different regions and seasons between both normalized indexes in future periods (Fig. 11) show that, even if certain local differences obviously exist and the amplitude of the forecasted changes differ, both indexes are globally coherent: overall, future years with a high MI correspond to the ones with a high CI, and vice versa. This suggests that the overall picture of decreasing avalanche activity on the largest spatio-temporal scale is fairly robust. By contrast, results obtained on smaller scales may well be more uncertain, for instance those concerning the southern French Alps for 2020-2050 and the northern French Alps for the late 21 st century for which the determination coefficient between the two indexes is very poor.

\subsubsection{Sensitivity to SRES scenarios}

The results obtained under the A1B scenario were compared to those corresponding to the $\mathrm{B} 1$ and $\mathrm{A} 2$ scenarios (IPCC, 2007) and are shown in Fig. 12. The plotted distributions concern the French Alps as a whole, for the full year and the two seasons. All of them show the decrease more markedly during spring and less clearly during winter, as discussed previously. Similarly, the increased dispersion of the distributions during winter exists for all the considered scenarios. Hence, with regard to the net changes that can be seen between the reference period (in blue) and the two future periods (mid and late 21st century, in green and red, respectively), the CI projections don't seem very sensitive to the selected scenario, especially for the mid 21 st century, for which the curves corresponding to the different scenarios are nearly superimposed. It can nevertheless be noted that, for the 2070-2100 period, scenario B1 (the more optimistic one) suggests weaker decreases for all seasons, with distributions closer to the mid 21 st century ones, whereas A2, the most pessimistic scenario, logically shows slightly enhanced decreases. Hence, interestingly, current climate policies may well have (slight) consequences for snow stability at the end of the century.

\section{Discussion, conclusions and outlook}

This study has proposed a detailed investigation of changes to be expected for the mid and late 21st century in snowpack variables and avalanche activity under climate warming in the French Alps, which is an area particularly sensitive in terms of avalanche hazard and, more generally, where socioeconomic impacts of snow conditions are considerable. 

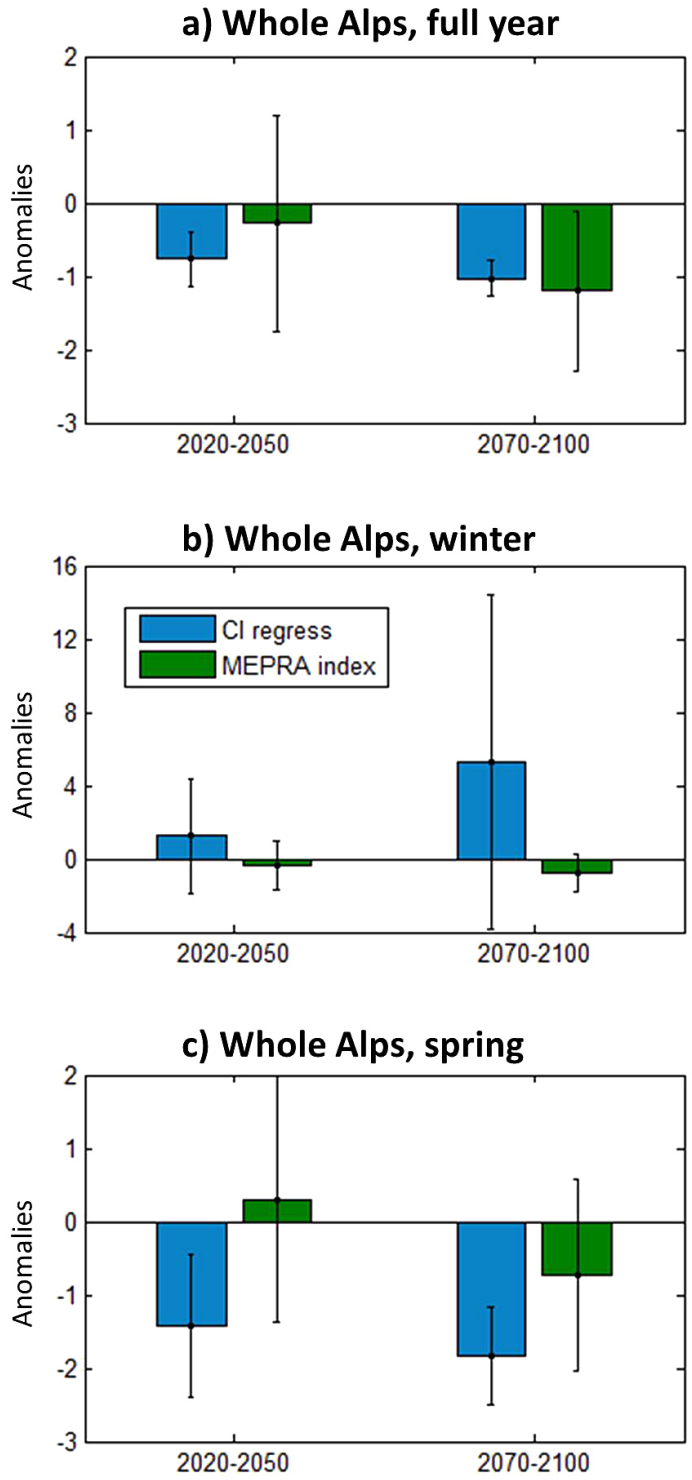

Figure 10. Changes in MEPRA index vs. changes in composite index regression model (in terms of anomalies) on the scale of the entire French Alps for the full avalanche year (a), and the winter (b) and spring (c) sub-periods.

Using downscaled and debiased simulations of a regional climate model feeding a detailed snow cover model and coupling them with a high-quality and long-term observational avalanche record, we have derived important results for this mountain environment and its economy and ecology in terms of anticipation of changes and risk management.

Indeed, forecasting a temperature increase and an associated decrease in snow is not revolutionary, but the results obtained for different elaborate snow variables (e.g. fresh- and wet-snow depths) are very refined with regard to the state of the art, especially in terms of latitudinal, altitudinal and seasonal gradients. Furthermore, as a continuation of Martin et al. (2001), who initiated future simulations of avalanche activity, those results may well be the first future projections based on a combination of climate and land surface modelling in mountainous environments which is, in turn, combined with avalanche observations in order to infer links with snow and meteorological conditions. The rigour of the statistical analyses (significance tests for marginal and joint distributions, etc.) and the usefulness of the indicators they provide (exceedance probabilities, variance ratios, etc.) constitute a rich and robust framework for the analysis of the obtained results.

While precipitations are expected to remain quite stationary (or at least with changes that could not be detected), temperature increase interacting with topography will control the amount of snow precipitation and snowpack characteristics, for instance the rate of a decrease in total and dry-snow depths. In a first approximation, latitude effects are generally of little importance with regard to interannual variability. Hence, at constant altitude, the southern French Alps are not significantly more affected than the northern French Alps in terms of snow depth decrease. This is somewhat unexpected, since it is generally postulated that the stronger solar radiation input received in southern locations would make the snowpack more sensitive to warming at a given altitude. Our results suggest that, on the scale of the north-south extension of the French Alps, this does not appear to be true.

As a general picture, four major developments are anticipated to take place over the next decades due to climate change: (i) the appearance of a wet snowpack at high elevations, even in the core of the winter season; (ii) more marked changes during the spring season as compared to the winter season; (iii) stronger changes for the late 21st century, but already (very) important for the mid century compared to the reference period 1961-1990; and (iv) a strong altitudinal control of changes (e.g. snow cover decrease affects low altitudes much more strongly). As a consequence of the latter point, different processes will presumably generate complex evolutions. For example, in winter, at high altitude, wet-snow depths are first expected to increase (they were close to 0 during the reference period) and then to decrease again when the warming is significant enough to prevent the formation of very deep snowpack.

Concerning the future projections of the composite index of avalanche activity, our main result is a projected general decrease in mean and interannual variability. Therefore, the probability of future seasons being as intense as the harsh winters of the reference period are very small, for instance by comparison to the less dramatic changes in snow and meteorological variables. The explanation is that avalanche activity changes result from changes in different snow variables which may intensify the response to the climatic signal as suggested by the very strong nonstationarities detected in the joint distributions (Table 8) and corresponding to most of the modelled composite indexes. 

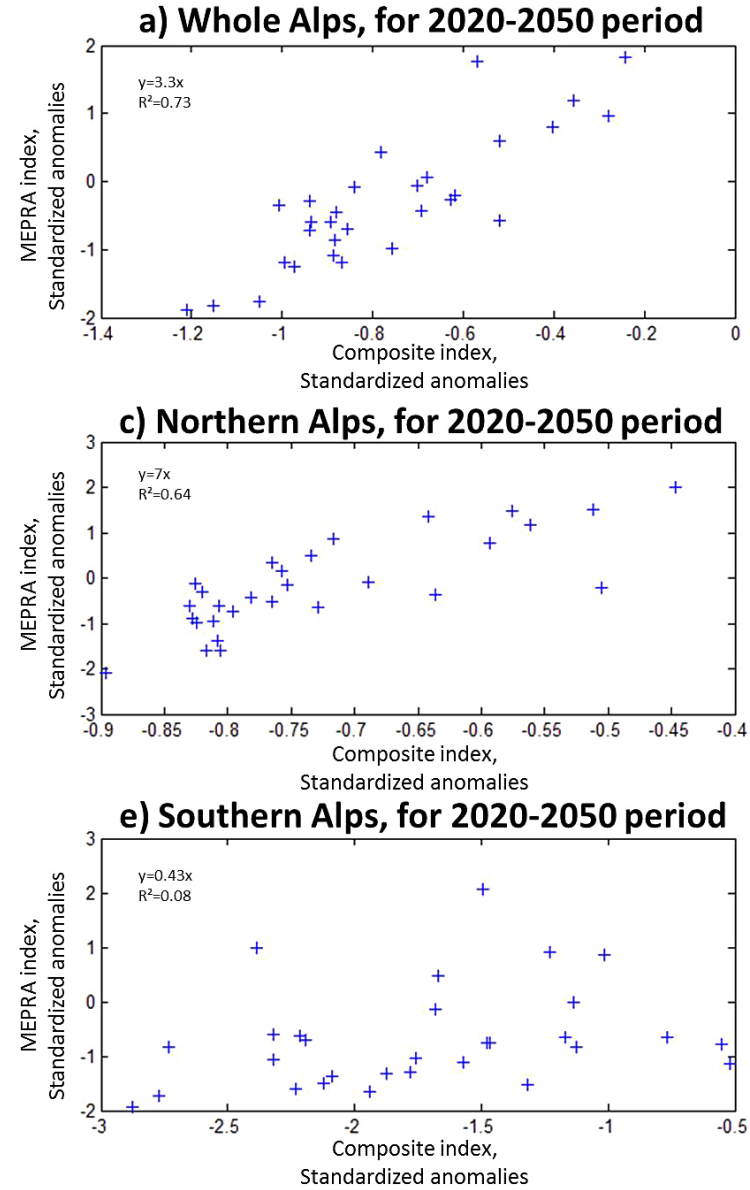

b) Whole Alps, for 2070-2100 period

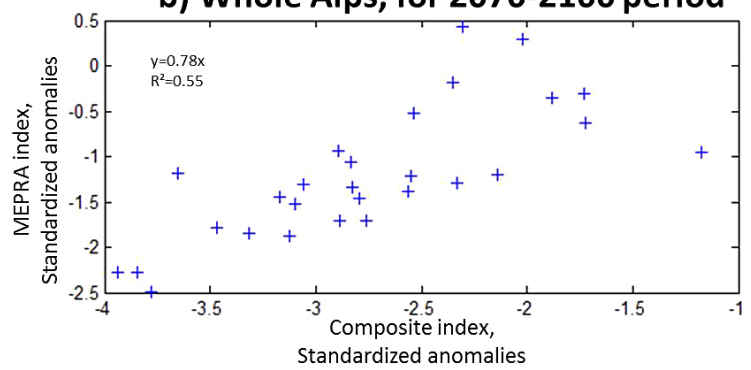

d) Northern Alps, for 2070-2100 period
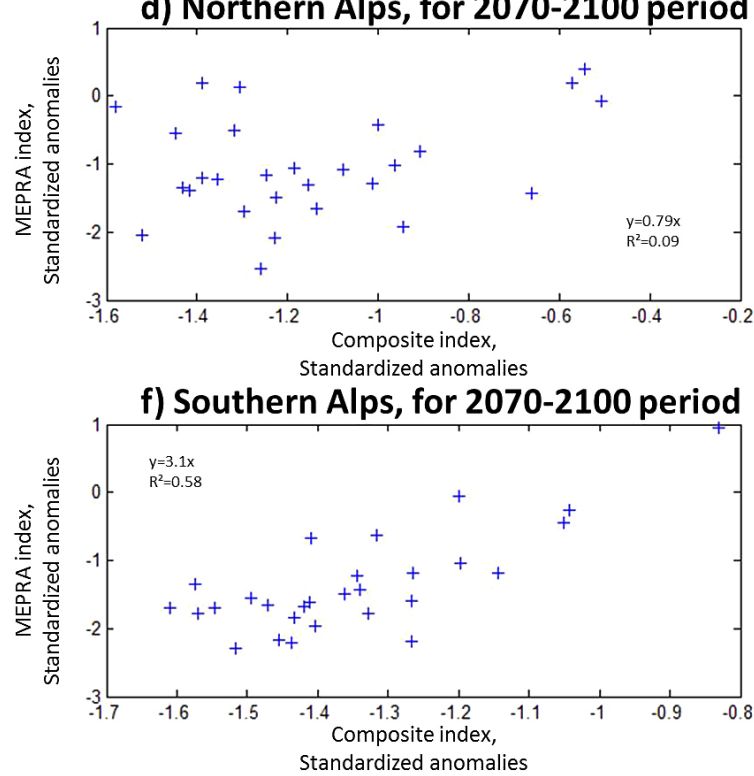

Figure 11. Scatter plots of standardized changes (as compared to reference period) in the MEPRA index vs. the CI regression model. The future periods 2020-2050 and 2070-2100 are, respectively, considered in the left and right panels. Subplots (a) and (b) concern the whole French Alps, (c) and (d) the northern French Alps and (e) and (f) the southern French Alps.

In more detail, this expected decrease is amplified in the spring season as compared to the full winter, and in the northern French Alps as compared to the southern French Alps. By contrast, a rather strong increase of avalanche activity in terms of interannual mean and, even greater, in terms of interannual variability is expected in winter, for instance in the higher-altitude massifs of the southern French Alps due to the fact that these distinct evolutions are mainly related to elevation effects on snow variables in a warming climate: during the 21 st century, spring snowpack and the related avalanche activity are found to disappear progressively from low to high altitudes. In addition, winter snowpack will show more and more variability, with possible wetting at increasingly high altitudes, making earlier wet-snow avalanche triggers possible in addition to winter dry-snow avalanche cycles, which are also still possible; this will eventually increase avalanche activity at that time, at least as long as a minimal snow cover is preserved. This picture seems in good agreement with the results of Lavigne et al. (2012) suggesting that increased avalanche activity has already taken place around the villages situated in the highest massifs of the French Alps.

Most of these changes in snow and avalanche variables are strong for the late 21 st century. It is again noteworthy that they are already more important than expected for the end of the mid century, compared with the 1960-1990 period, probably because the latter was relatively cold and snowy, as shown by winter climatologies of the French Alps (Durand et al., 2009b). Time series analyses have also shown relatively more intense avalanche activity on the whole-winter scale (Eckert et al., 2013) and even short glacial advances (Thibert et al., 2013) during this reference period. In contrast, an accelerated warming already occurred between 1985 and 2000 (e.g. Durand et al., 2009; Marty, 2008). Hence, it is very likely that the important changes assessed with regard to the mean 1960-1990 values have largely already occurred. Some of these changes may well slow down between the mid and late 21 st century because of contradictory effects and compensations such as wet-snow depth increase and decrease when warming goes on. 

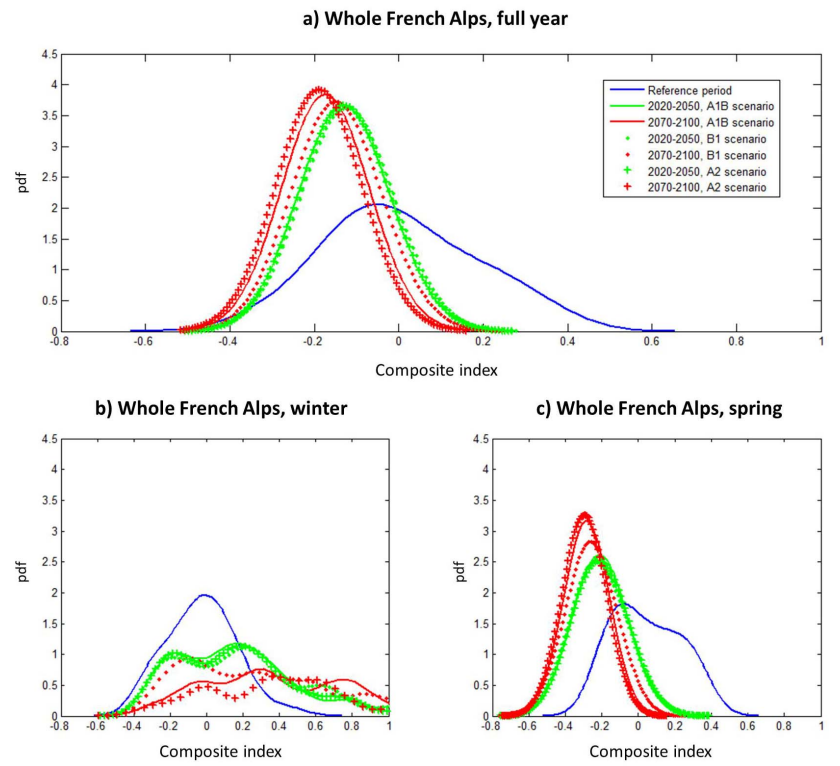

Figure 12. Distribution of the CI regression model for three IPCC scenarios for the mid and end of the 21st. The entire French Alps are considered, during the full avalanche year (a) and during the winter (b) and spring (c) seasons.

Also, forecasted changes in the mid 21st century do not seem to be influenced by the choice of the climatic IPCC (2007) SRES scenario, since only a slight difference between three rather different scenarios is visible at the end of the 21 st century. This apparent robustness has to be confirmed by the new, more accurate scenarios that have just been published (IPCC, 2013). From these multiple new scenarios, future work should expand on the results obtained here using a single GCM-RCM combination (one realization for each) to a wider range of large- and regional-scale climate scenarios. This would increase our confidence in the future predictions we make, given that using few climate scenarios and a single GCM-RCM chain does not allow us to encompass the entire range of uncertainty that downscaled climate projections carry (e.g. Lafaysse et al., 2014; Steger et al., 2013). We chose not to carry out this analysis in this paper since we focused on the methodological developments required to assess future changes in snow and avalanche variables and on the outcomes for our region of interest. Furthermore, handling the large-scale climate scenarios of the Fifth Assessment Report of IPCC (AR5) and adapting them to the topography of the French Alps represents significant work which has not been carried out yet. Note, however, that Piazza et al. (2014) have already studied the robustness of the projected snowfall changes in the French Alps to a very large number of high spatial resolution climate projections over the French Alps based on different downscaling approaches, but they did not carry this work out with the new SRES scenarios or within the SAFRAN representation of topography.
Beyond the question of the choice of the GCM-RCM chain and the SRES scenario, numerous uncertainty sources must be kept in mind while considering our results. Those related to snow and meteorological simulations in mountainous environment are detailed in Rousselot et al. (2012), while those specifically linked to the composite index and the linear regression approach are discussed in Castebrunet et al. (2012). However, a specific difficulty is worth discussing which arises from the combination of all these approaches in this paper. Indeed, it must be remembered that our regression models remain linear, which is arguably an oversimplified approximation of the true relationship between avalanche activity and snow and meteorological conditions in the reference climate. Despite the fact that the cross-validation is very conclusive (encouraging, but a mandatory requirement), it remains questionable whether or not these regression models can be trusted to assess avalanche activity under future changed climate since the real avalanche climate is, in reality, much more complex and clearly nonlinear. Our feeling is that, in a first approximation, the answer is that they can, since our statistical regression models seem able to adequately reproduce different avalanche triggering contexts, capturing elevation and latitude effects in a fairly intuitive (and hopefully realistic) way. Hence, by picking up a few meaningful variables, they may well capture the predominant physical processes relating avalanche to snowpack variables on each considered spatio-temporal scale, as suggested by the robustness of the cross-validation results.

The comparison with the MI, readily available in the future period from the projection of snow and meteorological conditions, can be seen as a way of confirming (or not) the projections in terms of CI. Overall, the CI and MI see rather similar decreasing trends, and scatter plots (Fig. 11) have shown that they see the same relative high/low activity in future years. Some differences have however been highlighted: the MI is characterized by a delayed reaction to changes (significantly at the end of the 21st century only), a lower shrinkage of the highest values, and regional/seasonal differences, such as the absence of winter or an increase in the southern massifs. These divergences are strong reasons to consider detailed projections with care and presumably undertake further work to better understand and refine them. They were, however, clearly expectable given the rather different ways future avalanche activity will be assessed in the future with the CI and through the MI. For instance, with regard to the $\mathrm{CI}$, the $\mathrm{MI}$ may better at taking into account the reduction of snow areas under warming and the "true" avalanche-climate relationship. On the other hand, the MI is not based on real observed activity, and if it describes intense avalanche activity during cold winter periods well, it is less well suited to represent sporadic snowmelt triggering as discussed in Castebrunet et al. (2012). The latter argument is the main reason for which we based our work mainly on the CI, since a warming climate is anticipated to favour such events. Nevertheless, since the MI captures the harsh "full winter" 
conditions well, projections concerning the evolution of the winters with the highest activity may well be more realistic on this point than those of the CI. Hence, the probability of exceeding the high values characteristic of the reference period may well decrease during the 21 st century, but presumably not as greatly and as fast as predicted by the CI, an important point from a risk assessment perspective.

Finally, it is worth noting that the threshold values and exceedance probabilities we assessed for the reference and future periods do not represent extreme avalanche episodes (i.e. clusters of events occurring on short spatio-temporal scales such 1-7 days in one or a couple of massifs) but seasons characterized by the strongest avalanche activity on larger spatial scales. Indeed this study has been realized with large-scale data, which involved snowpack characteristics and avalanche trigger numbers averaged/cumulated over long periods and large areas. To better apprehend avalanche risk in future, we therefore call for further analysis of future changes in (i) small spatial(path)-scale intensity variables, such as runout distances and pressures relevant for urbanism and road viability, and their link to snow and meteorological variables through e.g. friction parameters (Naaim et al., 2013); and (ii) 1-7-day, short intense avalanche episodes threatening mountain practitioners, as done with the MI in Giraud et al. (2013). Such episodes occur, e.g., during winter storms associating strong winds and extreme snowfall.

However, (i) and (ii) are more complicated problems as they involve (i) avalanche propagation and, in particular, its constraint by each site-specific topography; and (ii) a specific extreme-value statistical framework for snow-related variables (e.g. Gaume et al., 2013). In fact, both (i) and (ii) are related to the difficult question of finding an appropriate metric to represent, under current and future conditions, avalanche activity in terms of magnitude and frequency on various spatio-temporal scales. From this perspective, the CI developed here can arguably be seen as a rough first attempt which leaves the door largely open for additional developments.

Acknowledgements. This work was mainly done in the framework of the joint Météo France-Irstea ECANA project (http://www.avalanches.fr/projet-ecana/) funded by the French Ministry of the Environment (Risk Division-DGPR). It has also benefited from the results of the ANR SCAMPEI project (http://www.cnrm.meteo.fr/scampei/presentation_scampei/). The authors are grateful to C. Fierz, C. Marty and H. Gudmundsson whose comments and work helped us to produce a better paper.

Edited by: G. H. Gudmundsson

\section{References}

Ammann, W. and Bebi, P.: WSL Institute for Snow and Avalanche Reasearch SLF, Der Lawinenwinter 1999, Ereignisanalyse, SLF Davos. 588 pp., 2000.

Ancey, C., Gervasoni, C., and Meunier, M.: Computing extreme avalanches, Cold Reg. Sci. Technol., 39, 161-184, 2004.

Bavay, M., Lehning, M., Jonas, T., and Loewe, H.: Simulations of future snow cover and discharge in Alpine headwaters catchments, Hydrol. Process., 23, 95-108, 2009.

Bavay, M., Grünewald, T., and Lehning, M.: Response of snow cover and runoff to climate change in high Alpine catchments of Eastern Switzerland, Adv. Water Resour., 55, 4-16, doi:10.1016/j.advwatres.2012.12.009, 2013.

Beniston, M.: Variations of snow depth and duration in the Swiss Alps over the last 50 years: links to changes in large-scale climatic forcings, Clim. Change, 3, 281-300, 1997.

Beniston, M.: Climatic Change in Mountain Regions: A Review of Possible Impacts, Clim. Change, 59, 5-31, 2003.

Beniston, M.: Warm winter spells in the Swiss Alps: Strong heat waves in a cold season?, Geophys. Res. Lett., 32, L01812, doi:10.1029/2004GL021478, 2005a.

Beniston, M.: Mountain climates and climatic change: An overview of processes focusing on the European Alps, Pure Appl. Geophys., 162, 1587-1606, 2005b.

Beniston, M., Keller, F., and Goyette, S.: Snow pack in the Swiss Alps under changing climatic conditions: an empirical approach for climate impacts studies, Theor. Appl. Climatol., 74, 19-31, 2003.

Brown, R. D.: Northern hemisphere snow cover variability and change, 1915-97, J. Climate, 13, 2339-2355, 2000.

Brun, E., David, P., Sudul M., and Brunot, G.: A numerical model to simulate snow-cover stratigraphy for operational avalanche forecasting, J. Glaciol., 38, 13-22, 1992.

Castebrunet, H., Eckert, N., and Giraud, G.: Snow and weather climatic control on snow avalanche occurrence fluctuations over 50 yr in the French Alps, Clim. Past, 8, 855-875, doi:10.5194/cp-8855-2012, 2012.

Caussinus H. and Mestre O.: Detection and correction of artificial shifts in climate series, Appl. Statist., 53, 405-425, 2004.

Déqué, M.: Frequency of precipitation and temperature extremes over France in an anthropogenic scenario: Model results and statistical correction according to observed values, Global Planet. Change, 57, 16-26, doi:10.1016/j.gloplacha.2006.11.030, 2007.

Déqué, M. and Somot, S.: Variable resolution versus limited area modelling : perfect model approach. Research activities in atmospheric and oceanic modelling, CAS/JSC Working group on numerical experimentation, 37, 3.03-3.05, 2007.

Dumas, D.: Changes in temperature and temperature gradients in the French Northern Alps during the last century, Theor. Appl. Climatol., 111, 223-233, doi:10.1007/s00704-012-0659-1, 2012.

Durand, Y., Giraud, G., Brun, E., Mérindol, L., and Martin, E.: A computer-based system simulating snowpack structures as a tool for regional avalanche forecasting, J. Glaciology, 45, 469-484, 1999.

Durand, Y., Laternser, M., Giraud, G., Etchevers, P., Lesaffre, L., and Mérindol, L.: Reanalysis of 44 year of climate in the French Alps (1958-2002): methodology, model validation, climatology, and trends for air temperature and precipitation, J. Appl. Meteorol. Clim., 48, 29-449, 2009a. 
Durand, Y., Laternser, M., Giraud, G., Etchevers, P., Mérindol, L., and Lesaffre, B.: Reanalysis of 47 Years of Climate in the French Alps (1958-2005): Climatology and Trends for Snow Cover, J. Appl. Meteorol. Clim., 48, 2487-2512, 2009b.

Eckert, N., Parent, E., and Richard, D.: Revisiting statisticaltopographical methods for avalanche predetermination: Bayesian modelling for runout distance predictive distribution, Cold Reg. Sci. Technol., 49, 88-107, 2007a.

Eckert, N., Parent, E., Belanger, L., and Garcia, S.: Hierarchical modelling for spatial analysis of the number of avalanche occurrences at the scale of the township, Cold Reg. Sci. Technol., 50, 97-112, 2007b.

Eckert, N., Parent, E., Faug, T., and Naaim, M.: Bayesian optimal design of an avalanche dam using a multivariate numerical avalanche model, Stoch. Env. Res. Risk A, 23, 1123-1141, 2009.

Eckert, N., Parent, E., Kies, R., and Baya, H.: A spatio-temporal modelling framework for assessing the fluctuations of avalanche occurrence resulting from climate change: application to 60 years of data in the northern French Alps, Clim. Change, 101, 515-553, 2010a.

Eckert, N., Baya, H., and Deschâtres, M.: Assessing the response of snow avalanche runout altitudes to climate fluctuations using hierarchical modelling: application to 61 winters of data in France, J. Climate, 23, 3157-3180, 2010 b.

Eckert, N., Coleou, C., Castebrunet, H., Giraud, G., Deschatres, M., and Gaume, J.: Cross-comparison of meteorological and avalanche data for characterising avalanche cycles: the example of December 2008 in the eastern part of the French Alps, Cold Reg. Sci. Technol., 64, 119-136, 2010c.

Eckert, N., Keylock, C. J., Castebrunet, H., Lavigne. A., and Naaim, M.: Temporal trends in avalanche activity in the French Alps and subregions: from occurrences and runout altitudes to unsteady return periods, J. Glaciol., 59, 93-114, 2013.

Elsasser, H. and Buerki, R.: Climate change as a threat to tourism in the Alps, Clim. Res., 20, 253-257, 2002.

Falarz, M.: Long-term variability in reconstructed and observed snow cover over the last 100 winter seasons in Cracow and Zakopane (Southern Poland), Clim. Res., 19, 247-256, 2002.

Falarz, M.: Variability and trends in the duration and depth of snow cover in Poland in the 20th century, Int. J. Climatol., 24, 17131727, 2004.

Fierz, C., Armstrong, R. L., Durand, Y., Etchevers, P., Greene, E., McClung, D. M., Nishimura, K., Satyawali, P. K., and Sokratov, S. A.: The International Classification of Seasonal Snow on the Ground, in: IHP-VII Technical Documents in Hydrology No. 83, IACS Contribution No. 1, Paris, UNESCO-IHP, 80 pp., 2009.

Gaume J., Eckert, N., Chambon G., Eckert N., Naaim M., and Bel, L.: Mapping extreme snowfalls in the French Alps using MaxStable processes, Water Resour. Res., 49, 1079-1098, 2013.

Giraud, G.: MEPRA: An expert system for avalanche risk forecasting, ISSW Proc., Breckenridge, CO, Breckenridge, Colorado, USA, 4-8 October 1992, 97-104, 1993.

Giraud, G., Rousselot, M ., Merindol, L., Dombrowski-Etchevers, I., Durand, Y., Déqué, M., Castebrunet, H., and Eckert, N.: Adaptation of current modeled snow covers and avalanche hazards to future climate according several RCM scenarii: application to French Alps, International Snow Science Workshop proceedings. 7-11 October 2013, Grenoble-Chamonix, France, 1194-1200, 2013.
Gonseth, C.: Impact of snow variability on the Swiss winter tourism sector: implications in an era of climate change, Clim. Change, 119, 307-320, 2013.

Huntington, T. G., Hodgkins, G. A., Keim, B. D., and Dudley, R. W.: Changes in the Proportion of Precipitation Occurring as Snow in New England (1949-2000), J. Climate, 17, 2626-2636, 2004.

IPCC: Climate change 2007: The physical science basis, in: Contribution of working group I to the fourth assessment report of the Intergovernmental Panel on Climate Change, edited by: Solomon, S., Qin, D., Manning, M., Chen, Z., Marquis, M., Averyt, K. B., Tignor, M., and Miller, H. L., Cambridge University Press, Cambridge, UK and New York, NY, USA, 2007.

IPCC: Managing the Risks of Extreme Events and Disasters to Advance Climate Change Adaptation. A Special Report of Working Groups I and II of the Intergovernmental Panel on Climate Change, edited by: Field, C. B., Barros, V., Stocker, T. F., Qin, D., Dokken, D. J., Ebi, K. L., Mastrandrea, M. D., Mach, K. J., Plattner, G.-K., Allen, S. K., Tignor, M., and Midgley, P. M., Cambridge University Press, Cambridge, UK, and New York, NY, USA, 582 pp., 2012.

IPCC: Climate change 2013: The physical science basis, Final draft available at: http://www.climatechange2013.org/report/, last access: November 2013.

Jamard, A. L., Garcia, S., and Bélanger, V.: L'enquête permanente sur les Avalanches (EPA): Statistique descriptive générale des événements et des sites. DESS Ingénierie Mathématique Option Statistique, Université Joseph Fourier, Grenoble, France, 101 pp., available at: http://www.avalanches.fr/ (last access: September 2013), 2002.

Jomelli, V., Delval, C., Grancher, D., Escande, S., Brunstein, D., Hetu, B., Filion, L., and Pech, P.: Probabilistic analysis of recent snow avalanche activity and climate in the French Alps, Cold Reg. Sci. Technol., 47, 180-192, 2007.

Keiler, M., Knight, J., and Harrison, S.: Climate change and geomorphological hazards in the eastern European Alps, Phil T. R. Soc. Lond., 368, 2461-2479, 2010.

Keller, F., Goyette, S., and Beniston, M.: Sensitivity analysis of snow cover to climate change scenarios and their impact on plant habitats in alpine terrain, Clim. Change, 72, 299-319, 2005.

Lafaysse, M., Hingray, B., Mezghani, A., Gailhard, J., and Terray, L.: Internal variability and model uncertainty components in future hydrometeorological projections: The Alpine Durance basin, Water Resour. Res., 50, 3317-3341, doi:10.1002/2013WR014897, 2014.

Laternser, M. and Schneebeli, M.: Long-term snow climate trends of the Swiss Alps (1931-99), Int. J. Climatol., 23, 733-750, 2003.

Lavigne, A., Bel, L., Parent, E., and Eckert, N.: A model for spatiotemporal clustering using multinomial probit regression: application to avalanche counts in the French Alps, Envirometrics, 23, 522-534, 2012.

Lavigne, A., Eckert, N., Bel, L., and Parent, E.: Adding expert contribution to the spatio-temporal modeling of avalanche activity under different climatic influences, J. R. Stat. Soc., accepted, 2014.

Lazar, B. and Williams, M.: Climate change in western ski areas: Potential changes in the timing of wet avalanches and snow quality for the Aspen ski area in the years 2030 and 2100, Cold Reg. Sci. Technol., 51, 219-228, 2008. 
López-Moreno, J. I., Goyette, S., and Beniston, M.: Impact of climate change on snowpack in the Pyrenees: Horizontal spatial variability and vertical gradients, J. Hydrol., 374, 384-396, 2009.

López-Moreno, J. I., Goyette, S., Vicente-Serrano, S. M., and Beniston, M.: Effects of climate change on the intensity and frequency of heavy snowfall events in the Pyrenees, Clim. Change, 105, 489-508, 2011.

Martin, E., Brun, E., and Durand, Y.: Sensitivity of the French Alps snow cover to the variation of climatic variables, Ann. Geophys., 12, 469-477, doi:10.1007/s00585-994-0469-6, 1994.

Martin, E., Giraud, G., Lejeune, Y., and Boudart, G.: Impact of climate change on avalanche hazard, Ann. Glaciol., 32, 163-167, 2001.

Marty, C.: Regime shift of snow days in Switzerland, Geophys. Res. Lett., 35, L12501, doi:10.1029/2008GL033998, 2008.

Marty, C. and Meister, R.: Long-term snow and weather observations at Weissfluhjoch and its relation to other highaltitude observatories in the Alps, Theor. Appl. Climatol., 1-11, doi:10.1007/s00704-012-0584-3, 2012.

McCabe, G. J. and Wolock, D. M.: Long-term variability in Northern Hemisphere snow cover and associations with warmer winters, Clim. Change, 99, 141-153, 2010.

Mitterer, C., Hirashima, H., and Schweizer, J.: Wet-snow instabilities: comparison of measured and modelled liquid water content and snow stratigraphy, Ann. Glaciol., 52, 201-208, 2011.

Morán-Tejeda, E., López-Moreno, J. I., and Beniston, M.: The changing roles of temperature and precipitation on snowpack variability in Switzerland as a function of altitude, Geophys. Res. Lett., 40, 2131-2136, doi:10.1002/grl.50463, 2013.

Mote, P. W.: Trends in snow water equivalent in the Pacific Northwest and their climatic causes, Geophys. Res. Lett., 30, 1601, doi:10.1029/2003GL017258, 2003.

Mougin, P.: Les avalanches en Savoie. Ministère de l'Agriculture, Direction Générale des Eaux et Forêts, Service des Grandes Forces Hydrauliques, Paris, Tech. Rep., 175-317, 1922.

Naaim, M., Durand, Y., Eckert, N., and Chambon, G.: Dense avalanche friction coefficients: influence of physical properties of snow, J. Glaciol., 59, 771-782, 2013.

ONERC: Changements climatiques dans les Alpes: Impacs et risques naturels, Rapport technique, 86 pp., available at: http: //www.risknat.org/docs/Technical\%20Report\%20N\%B01.pdf (last access: November 2013), 2008.

Piazza, M., Boé, J., Terray, L., Pagé, C., Sanchez-Gomez, E., and Dequé, M: Projected 21st century snowfall changes over the French Alps and related uncertainties, Clim. Change, 122, 583594, doi:10.1007/s10584-013-1017-8, 2014.
Pielmeier, C., Techel, F., Marty, C., and Stucki, T.: Wet snow avalanche activity in the Swiss Alps - trend analysis for midwinter season, Proceedings of the International Snow Science Workshop, Grenoble and Chamonix, 1240-1246, 2013.

Räisänen, J.: Warmer climate: less or more snow?, Clim. Dynam., 30, 307-319, 2008.

Rangwala, I. and Miller, J. R.: Climate change in mountains: a review of elevation-dependent warming and its possible causes, Clim. Change, 114, 527-547, 2012.

Richard, D., Marcepoil, E., and Boudières, V.: Changement climatique et développement des territoires de montagne: quelles connaissances pour quelles pistes d'action?, Website Rev. Geogr. Alp., available at: http://rga.revues.org/index1322.html (last access: November 2013), 2010.

Rousselot, M., Durand, Y., Giraud, G., Mérindol, L., DombrowskiEtchevers, I., Déqué, M., and Castebrunet, H.: Statistical adaptation of ALADIN RCM outputs over the French Alps - application to future climate and snow cover, The Cryosphere, 6, 785805, doi:10.5194/tc-6-785-2012, 2012.

Saporta, G. : Probabilités, analyse des données et statistique, Technip, 2nd Edn., Broché, Paris, France, 622 pp., 2006.

Serquet, G., Marty, C., Dulex J/-P., and Rebetez, M.: Seasonal trends and temperature dependence of the snowfall/precipitationday ratio in Switzerland, Geophys. Res. Lett., 38, L07703, doi:10.1029/2011GL046976, 2011.

Steger, C., Kotlarski, S., Jonas, T., and Schär, C.: Alpine snow cover in a changing climate: A regional climate model perspective, Clim. Dynam., 41, 735-754, 2013.

Thibert, E., Eckert, N., and Vincent, C.: Climatic drivers of seasonal glacier mass balances: an analysis of 6 decades at Glacier de Sarennes (French Alps), The Cryosphere, 7, 47-66, doi:10.5194/tc-7-47-2013, 2013.

Uppala, S., Kallberg, P. W., Hernandez, A., Saarinen, S., Fiorino, M., Li, X., Onogi, K., Sokka, N., Andrae, U., and Da Costa Bechtold, V.: ECMWF, "ERA-40: ECMWF 45-years reanalysis of the global atmosphere and surface conditions 1957-2002", ECMWF Newsletter, No. 101, ECMWF, Reading, UK, 2-21, 2004.

Valt, M. and Cianfarra, P.: Recent snow cover variability in the Italian Alps, Cold Reg. Sci. Technol., 64, 146-157, 2010.

Wilby, R. L., Wigley, T. M. L., Conway, D., Jones, P. D., Hewitson, B. C., Main, J., and Wilks, D. S.: Statistical downscaling of generalcirculation model output: a comparison of methods, Water Ressour. Res., 34, 2995-3008, 1998. 